ISSN: 0514-7336 — ISSN electrónico: 2386-3943

DOI: https://doi.org/10.14201/zephyrus2020851536

\title{
EL HIPOGEO DEL CARRER PARÍS (CERDANYOLA DEL VALLÈS, BARCELONA): ESTUDIO MICROMORFOLÓGICO DE UN DEPÓSITO FUNERARIO DEL NEOLÍTICO FINAL Y CALCOLÍTICO CAMPANIFORME
}

\section{The hypogeum from the Carrer Paris (Cerdanyola del Vallès, Barcelona): micromorphological study of a Late Neolithic and Bell-Beaker funeral deposit}

Joan Carbonell Roca*, M. Mercè Bergadì*, Joan Francès Farrè** y Marc Guardia i Llorens**

* Seminari d'Estudis i Recerques Prehistóriques (serp). Dpto. de Historia y Arqueología. Univ. de Barcelona. Cl Montalegre, 6.08001 Barcelona.Correo-e: carbonell@ub.edu; bergada@ub.edu. id orcid: https://orcid.org//00000003-3637-7793; https://orcid.org//0000-0002-6216-3249

** Col.lectiu de Recerques Arqueològiques (crac). Cl València, 19. 08290 Cerdanyola del Vallès (Barcelona). Correo-e: francesfj@cerdanyola.cat; mgllorens@granollers.cat.id orcid: https://orcid.org//0000-0001-6496-3410; https://orcid.org//0000-0002-9651-270X

Recepción: 26/04/2020; Revisión: 15/05/2020; Aceptación: 3/06/2020

Resumen: En este artículo se presentan las principales aportaciones de la micromorfología al estudio del hipogeo del Carrer París (Cerdanyola del Vallès, Barcelona), datado entre 2878-2206 cal BC. El hipogeo del Carrer París comienza a utilizarse antes de la adopción del complejo campaniforme localizándose un primer nivel de inhumación colectiva propio del Neolítico Final-Calcolítico. Le seguirán tres episodios de inhumaciones asociadas a vasos campaniformes de diferentes tipologías. El uso continuado del sepulcro pone de manifiesto la evolución de las prácticas funerarias propias del Neolítico hacia una progresiva tendencia a la individualización de las inhumaciones paralela a la adopción de las cerámicas campaniformes.

Del estudio realizado se deduce que el hipogeo fue concebido y construido con suficiente antelación a su uso y existió un ritual funerario relacionado con el fuego anterior a su utilización como sepulcro. Además, la estructura se colmató por sedimentación geogénica y se han identificado los procesos postdeposicionales que afectaron a las inhumaciones. En resumen, creemos que la micromorfología de suelos. En resumen, creemos que la micromorfología de suelos constituye una herramienta esencial para el estudio e interpretación de contextos funerarios. En este caso, ha permitido identificar y caracterizar mejor el proceso constructivo y funerario de este tipo de enterramientos prehistóricos en el NE peninsular.

Palabras clave: Geoarqueología; enterramiento; proceso constructivo; Neolítico Final; Campaniforme.

ABSTRACT: This paper presents the contributions of micromorphology to the study of the hypogeum of Carrer Paris (Cerdanyola del Vallès, Barcelona), dated between 2878 and 2206 cal BC. The hypogeum of Carrer Paris was first used for a collective inhumation during the Late Neolithic. Afterward it was used again during the Bell-Beaker Chalcolithic for three different burial episodes including Bell-Beaker vessels.. The continued use 
of the sepulcher highlights the evolution of common funeral practices in the Neolithic towards a progressive tendency to individualize burials parallel to the adoption of bell- shaped vessels.

The study shows that the hypogeum was conceived and constructed well in advance of its use as well as the existence of a funeral ritual related to the use of fire prior to its use as a sepulchre. In addition, the sedimentary infilling of the structure by geogenic processes and identifies the post-depositional processes that the burials have suffered. In summary, soil micromorphology has proved to be an essential tool for the study and interpretation of funerary contexts. In this case, it has allowed us to identify and characterize better the constructive and funerary process of this type of prehistoric burials in the peninsular Northeast.

Key words: Geoarchaeology; hypogeum; constructive process; Late Neolithic; Bell Beaker Culture.

\section{Introducción ${ }^{1}$}

Esta investigación analiza el relleno sedimentario del hipogeo del Carrer París mediante la micromorfología, es decir, el estudio de los sedimentos y suelos a través del microscopio petrográfico. Los estudios microestratigráficos vinculados a la Prehistoria Reciente están siendo cada vez más generalizados, pero, frecuentemente, se refieren a niveles de estabulación, suelos de ocupación, pavimentos, hogares, silos, etc. (Courty et al., 1989; Ge et al., 1993; Bergadà, 1998; Angelucci et al., 2009; Macphail y Goldberg, 2010, 2018; Polo-Díaz, 2010; Banerjea et al., 2015; Bergadà et al., 2018;

1 Este trabajo ha sido posible gracias al proyecto "El Hipogeo Calcolítico de la Calle París (Cerdanyola del Vallès) en el contexto de la problemática de la génesis del complejo campaniforme en la Europa Meridional: Estudio bioantropológico y arqueológico", financiado por el Ayto. de Cerdanyola y cuenta con la colaboración del Servei d'Arqueologia de la Direcció General del Patrimoni Cultural de la Generalitat de Catalunya y la Oficina del Patrimoni Cultural de la Diput. de Barcelona; también, se inscribe en los proyectos HAR2017-86509-P y sGR2017-00011. J. C. R. goza de un contrato predoctoral FPU del Ministerio de Educación, Cultura y Deporte. Quisiéramos agradecer al Dr. F. X. Oms, del serp-Dpto. de Historia y Arqueología de la Univ. de Barcelona la calibración de las dataciones radiocarbónicas, la elaboración del análisis bayesiano de las mismas y los sugerentes comentarios del artículo. Finalmente, agradecemos a la unidad de Microscopía óptica avanzada de los Centros Científicos y Tecnológicos (сCiтuB) de la Univ. de Barcelona la microscopía de fluorescencia facilitada y al SCT de Micromorfología y Análisis de imágenes de la Univ. de Lleida la elaboración de las láminas delgadas.
Mateu et al., 2019)2 ${ }^{2}$ Su aplicación al estudio de las estructuras funerarias ha sido muy limitada centrándose, con frecuencia, en la preservación de restos humanos y en los procesos postdeposicionales relacionados con dichos contextos (Bergadà et al., 2015; Brönnimann et al., 2018).

El hipogeo del Carrer París contiene una secuencia estratigráfica ciertamente singular. En ella se distingue la evolución de las inhumaciones colectivas hacia una paulatina individualización. El material localizado y las dataciones realizadas permiten situar perfectamente una fase inicial del hipogeo en el Neolítico Final y una utilización posterior paralela a la irrupción del complejo campaniforme. Destaca sobremanera la gran cantidad de estos característicos vasos conservados en un excelente estado, tanto de estilo internacional como regional, y bien definidos estratigráficamente (Fig. 1). De más antiguo a más moderno, encontramos 2 vasos de estilo marítimo -UE 5-, 1 de estilo marítimo y 2 epimarítimos -UE 2- y un vaso campaniforme regional de estilo pirenaico - UE 1-. Toda esta información permite reflexionar acerca del cambio funerario, sus implicaciones sociales y sobre la secuencia cronológica del Campaniforme en el NE peninsular ${ }^{3}$. Cabe destacar en este sentido que el estudio antropológico preliminar ha evidenciado que la mayoría de las

2 Cf. también Polo Díaz, A. (2010): Rediles prehistóricos y uso del espacio en abrigos bajo roca en la Cuenca Alta del Ebro: geoarqueología y procesos de formación durante el Holoceno. Tesis doctoral inédita defendida en 2010 en la Univ. del País Vasco-Euskal Herriko Unibertsitatea.

3 En adelante se recurre sistemáticamente a la abreviatura UE/UUEE para referir la/s unidad/des estratigráfica/s. 


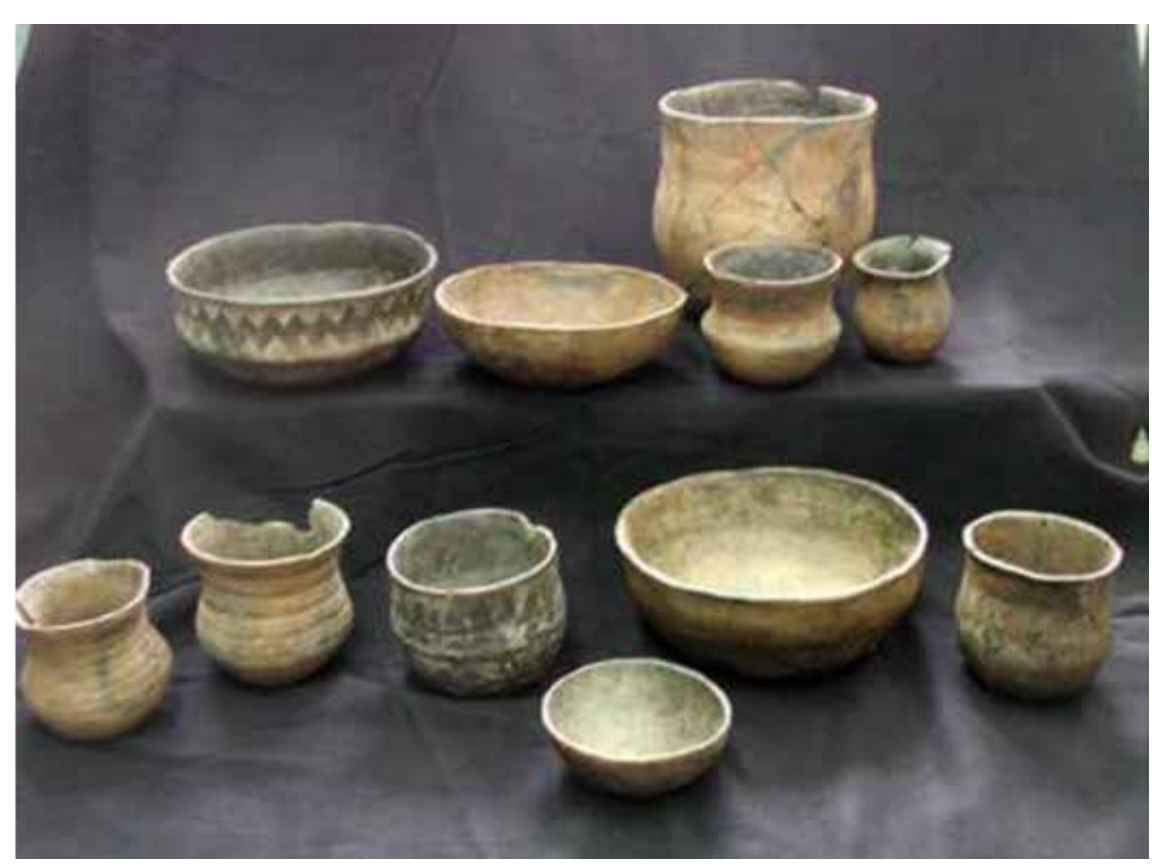

FIG. 1. Conjunto de algunos de los vasos cerámicos del hipogeo.
Oms et al., 2018; Roig Buxó et al., 2008). Por este motivo el hipogeo del Carrer París constituye un yacimiento excepcional para corregir este vacío de información, tanto a nivel cronocultural como microestratigráfico, sobre todo, vinculado a la esfera funeraria.

En referencia al periodo Campaniforme, diversos especialistas han cuestionado el esquema evolutivo planteado en cuatro fases (Guilaine, 1958, 1967, 1984, 2019; Guilaine et al., 2001) para el $s$ de Francia y Cataluña. Incluso algunos han llegado a plantear que entre el 2800 y el 2400 вс no es inhumaciones asociadas a estos vasos correspondían a mujeres ${ }^{4}$.

Los periodos del Neolítico Final, y muy especialmente del Campaniforme, presentan una escasez de secuencias estratigráficas y dataciones radiocarbónicas fiables que muestren claramente su evolución en el NE peninsular (Martín, 2001; Soriano, 2013). Esta problemática se debe a que gran parte de los yacimientos fueron excavados durante los primeros años del s. xx, con pérdida de información por la metodología propia de la época. Así, los materiales campaniformes en contexto acostumbran a ser escasos y más aún las series estratigráficas que permiten constatar una ocupación/utilización continuada en el tiempo (Clop, 2005). Sin embargo, en los últimos años se han documentado algunos yacimientos, sobre todo hábitats, que están cambiando el vacío de conjuntos campaniformes estrictos (Carlús y De Castro, 2017; López et al., 2015;

4 Rissech, C.: Inventari i la classificació 25 individus del jaciment arqueològic del carrer París de Cerdanyola del Vallès (Vallès Occidental). Informe inédito entregado en 2019 en la Dir. Gral. de Patrim. Cultural de la Generalitat de Catalunya. posible separar el Estilo Marítimo -Internacionalde los estilos incisos -Regionales- del s de Francia a partir de dataciones radiocarbónicas (Salanova, 1998; Cardoso, 2019).

Nuestro propósito en este artículo es dar a conocer los resultados del estudio micromorfológico efectuado en el hipogeo del Carrer París. Por su carácter excepcional, uno de los primeros objetivos será mostrar qué procesos intervinieron en la formación del relleno del hipogeo. De esta manera, se reconstruye su historia evolutiva y la dinámica de uso de sus diferentes niveles. Por otra parte, también ahonda en los diferentes aspectos relacionados con el mundo funerario del Neolítico Final y Calcolítico Campaniforme en cuanto al ritual de enterramiento y al tratamiento de las inhumaciones.

\section{El hipogeo del Carrer París}

\subsection{Contexto geológico y geográfico}

El hipogeo del Carrer París -94 m.s.n.m. y coordenadas UTM x: $427234 \mathrm{~m}$, y: $4594591 \mathrm{~m}$ 


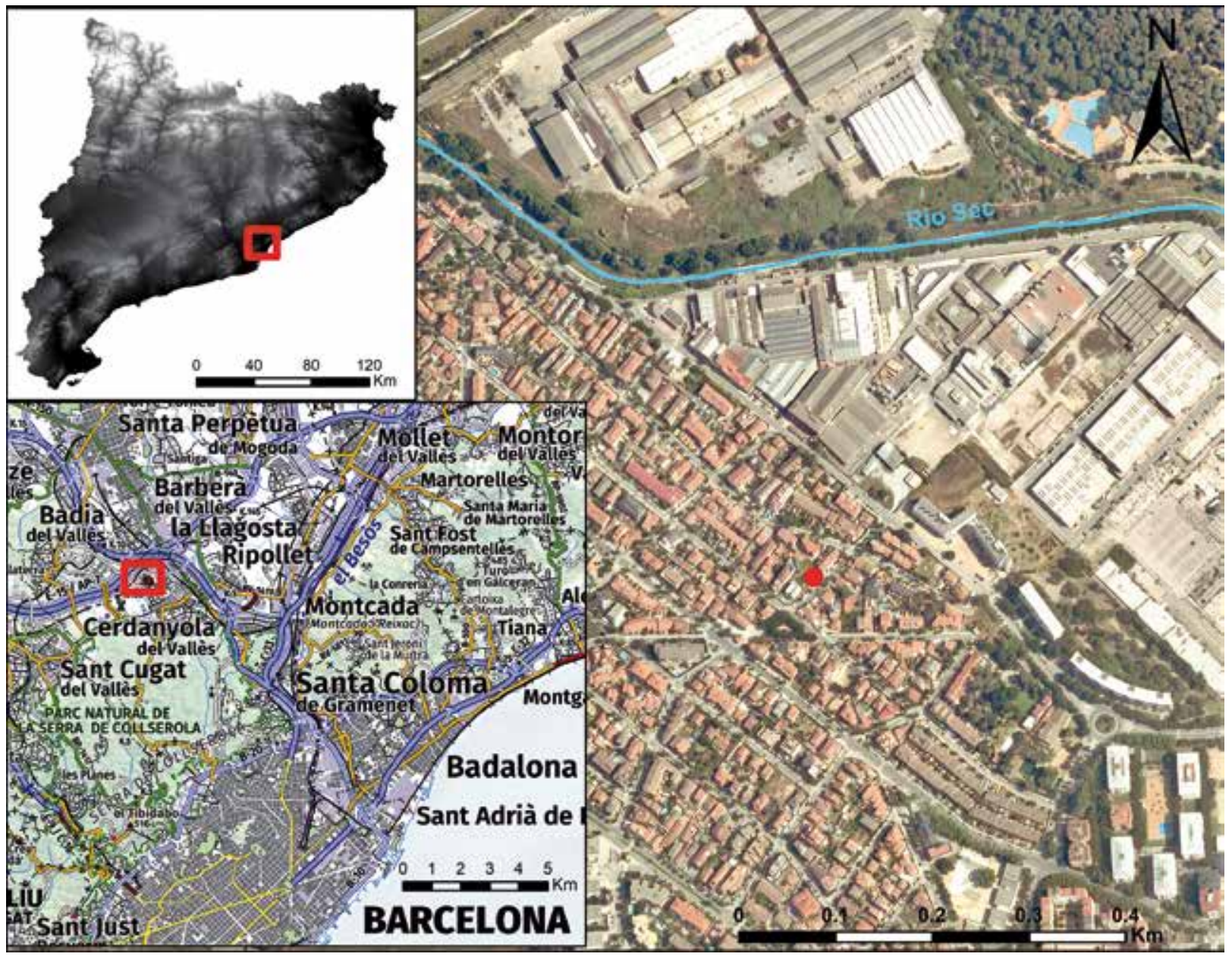

Fig. 2. Localización del hipogeo del Carrer Paris, Cerdanyola del Vallès, Barcelona.

ETRS89- se localiza en el municipio de Cerdanyola del Vallès, Barcelona, dentro de la cuenca del Vallès-Penedès, en el tramo central de la depresión prelitoral (Fig. 2). Se encuentra delimitada por las cordilleras Litoral y Prelitoral que discurren de forma paralela a lo largo de la costa catalana, desde el Ampurdán hasta Tortosa.

La zona objeto de estudio forma una llanura ondulada que configura crestas alargadas -Serra de Galliners, Serra de Sant Iscle, etc.- con vertientes suaves y redondeadas compuestas por materiales blandos y arcillosos, surcados por torrentes de agua procedente de las montañas que la rodean (De Mas, 1989).

Los sedimentos que rellenan la cuenca son materiales detríticos del Neógeno y el Cuaternario, principalmente procedentes de la erosión de los torrentes. Se localizan rocas metamórficas, volcánicas y plutónicas del Paleozoico, rocas terrígenas y carbonatadas del Mesozoico y rocas terrígenas del Paleógeno que conforman la cordillera Prelitoral. Sin embargo, en el sector de Sant Cugat-Cerdanyola también aparecen cuñas de facies marinas del Mioceno Medio (De Mas, 1998).

El hipogeo aprovecha una suave pendiente que ofrece una terraza del río Sec. La parte inferior de esta terraza está constituida por cantos rodados y gravas con una matriz arenosa-arcillosa de color rojizo y su parte superior está ligeramente cementada por carbonatos. Su composición litológica y 
mineralógica es variada, encontrando clastos de calizas, pizarras, cuarzos, areniscas y microconglomerados.

Encima aparecen materiales finos coluviales ${ }^{5}$, también recortados por la cámara funeraria, que aumentan de potencia en dirección o. Es un horizonte de arcillas arenosas de color anaranjado, fuertemente carbonatado, sobre el cual hay otro horizonte de arcillas rojizas muy plásticas (Francès et al., 2006).

Esta secuencia configura una evolución edáfica que, de muro a techo, es la siguiente: arcillas rojas -illita y kaolinita- que da lugar a un Horizonte в fersialítico de unos $50-75 \mathrm{~cm}$, coronado por un encostramiento de $20 \mathrm{~cm}$ nodular y discontinuo. A continuación, aparece la misma matriz con un progresivo encostramiento calcáreo nodular de menor importancia que el anterior ${ }^{6}$.

\subsection{Registro arqueológico}

El hipogeo del Carrer París fue descubierto durante los trabajos de cimentación de unos edificios de esta calle. La intervención arqueológica se inició a mediados de 2003 y finalizó a finales de 2004. Consistió en la excavación de la estructura, el registro de las unidades estratigráficas, de los materiales y restos aparecidos; así como el muestreo antracológico, sedimentológico y micromorfológico para su posterior estudio (Fig. 3).

A pesar de las diferentes afectaciones y de su conservación parcial, pudo precisarse que se trataba de un hipogeo de forma ovoide, de 5,20 m de largo x 2 de ancho x 1,20 de profundidad, cuya entrada se había perdido. Sin embargo, se pudo determinar que el acceso al hipogeo estaba en el sector oriental, ya que en todas las fases de utilización aparecía una misma zona libre de restos humanos y era evidente su cierre en el extremo opuesto. Durante la intervención de campo se determinaron hasta 4 episodios de inhumación (Fig. 4) (Francès et al., 2006).

5 De Mas, D.: L'Evolució geomorfològica Quaternària del Vallès occidental. Tesis doctoral inédita defendida en 1983 en la Univ. de Barcelona.

6 De Mas, op. cit., n. 3.
En la base del hipogeo se documentó un recorte del sustrato natural de forma ovalada que, al estar bajo la calle, no pudo ser excavado en su totalidad (UE 19) recuperándose solo un fragmento de cerámica informe. Encima se localizaron tres niveles -UUEe 18, 17 y 15-, que se extendían solo en la parte central de la cámara, con abundantes restos de cenizas y carbones, especialmente en la UE 15 , donde se recuperó gran número de restos antracológicos; el $88 \%$ de los cuales pertenecían al género Quercus $^{7}$-roble-. Esta unidad fue datada mediante una muestra de carbón (Fig. 5) en 2859-2579 cal вС $-1 \sigma-$, aunque el problema de la madera antigua podría provocar un resultado algo anterior a lo esperado. No se pudo determinar si la combustión se hizo in situ o en el exterior y se apuntó la posibilidad de que fuera un posible ritual de preparación del hipogeo previo a su uso.

Sobre ellas apareció el primer episodio de inhumación -UE 12-. Se trataba de un enterramiento colectivo a partir de inhumaciones sucesivas dispuestas en dos posibles espacios, uno de los cuales no se excavó al quedar bajo la calle. En general, los cuerpos aparecieron en conexión anatómica, en decúbito lateral, las extremidades dobladas y los huesos alterados, especialmente en la base de la estructura. La disposición de los cuerpos se adaptaba a la morfología del hipogeo ocupando toda la superficie disponible y amontonándose una vez ocupado todo el espacio (Francès et al., 2006).

Hasta el momento se ha determinado para esta unidad un NMI superior a 40, aunque debajo de la calle, donde queda por excavar una parte de la estructura, probablemente habría más restos. Seguramente habría que añadir a estos las inhumaciones perdidas o desplazadas por una reorganización posterior del espacio -UE 5- (Francès et al., 2006). En el marco de un estudio sobre genética (Olalde et al., 2018), se obtuvieron tres dataciones de sendos individuos de esta unidad (Fig. 5), que sitúan la

7 Piqué, R. y Mensua, C.: Informe de l'anàlisi de les restes de fusta carbonitzada del jaciment del carrer París (Cerdanyola del Vallès). Informe inédito depositado en 2005. 


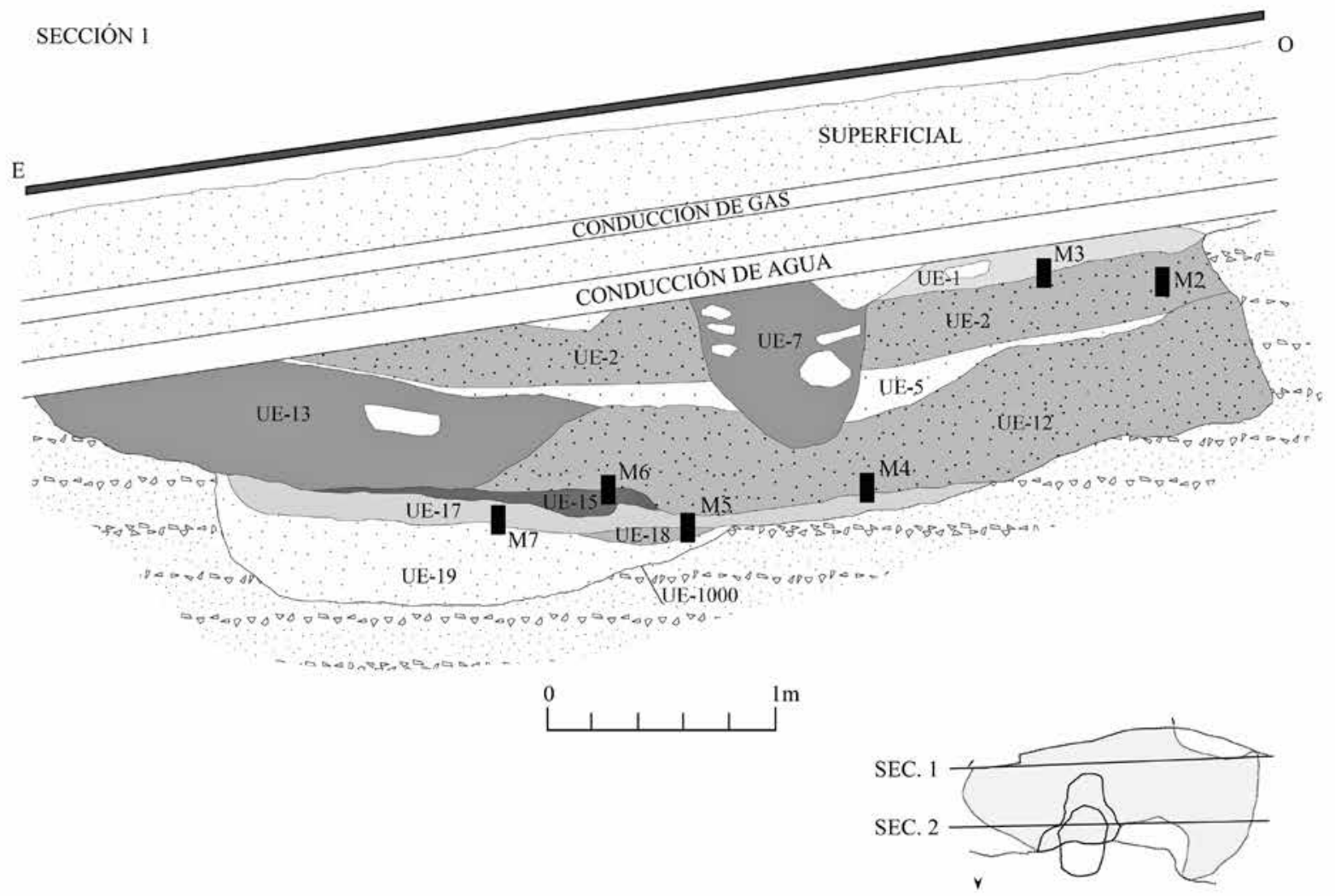

SECCIÓN 2
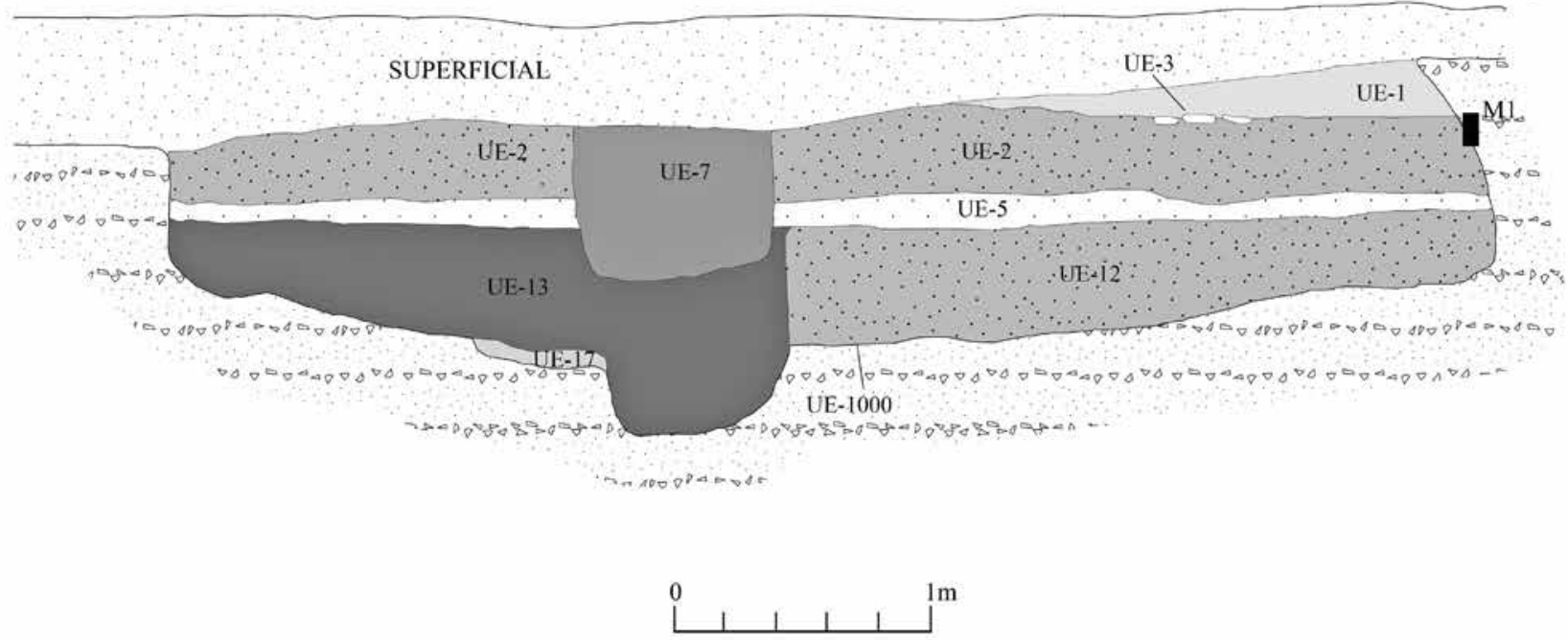

Fig. 3. Secciones del hipogeo del Carrer París (E-O) con la ubicación de las muestras micromorfológicas recogidas. 

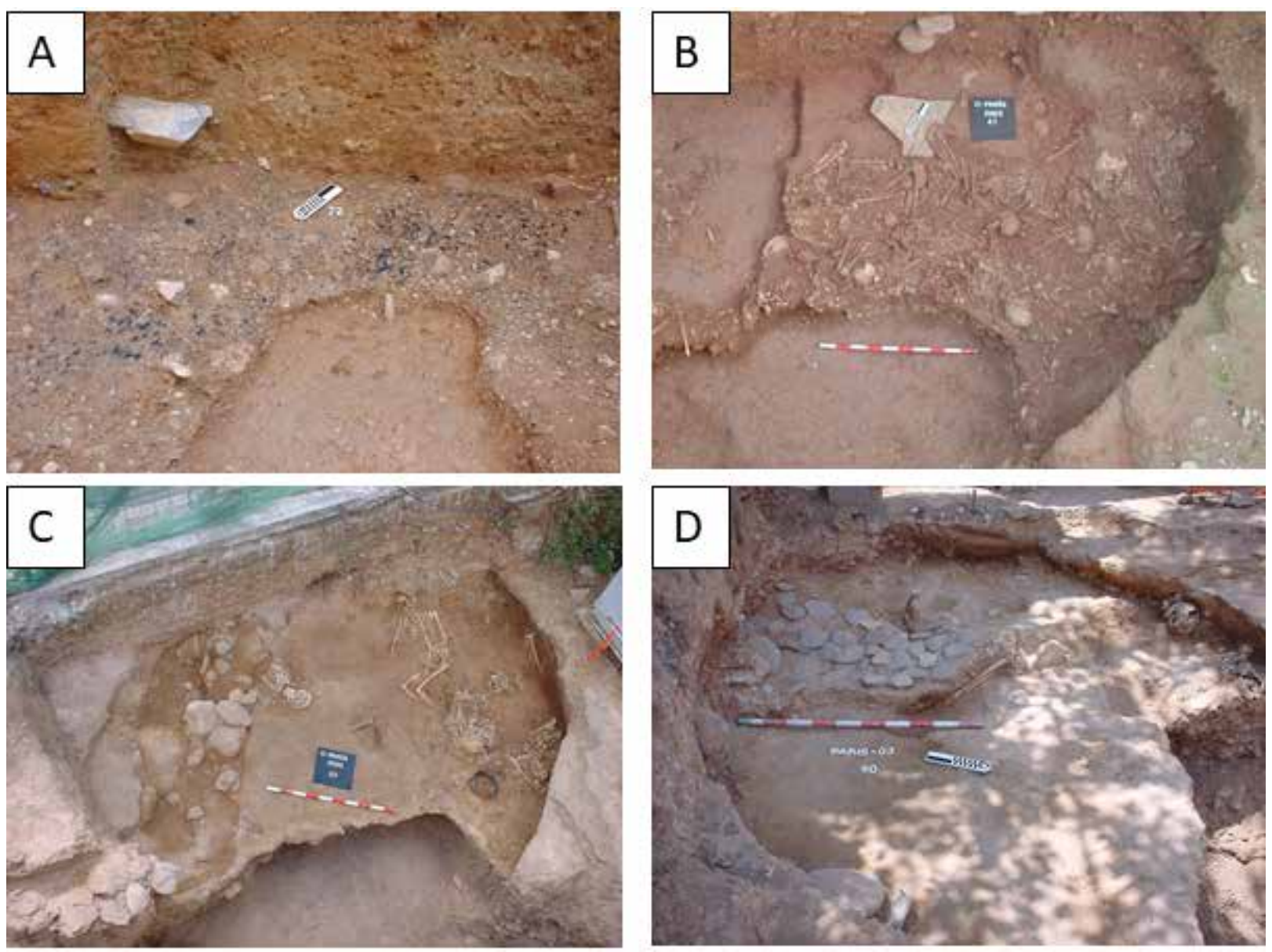

Fig. 4. Algunos de los niveles de preparación y episodios de inhumación documentados en el hipogeo del Carrer París durante la excavación: A) niveles de preparación antes del primer episodio de inhumación con abundantes restos de carbones; B) primer episodio de inhumación -UE 12-. Inhumaciones colectivas sucesivas del Neolítico Final; C) proceso de excavación del segundo episodio de inhumación -UE 2-. Inhumaciones individuales asociadas a cerámica campaniforme internacional; D) cuarto episodio de inhumación -UE 1-. Inhumaciones individuales encima de un empedrado de guijarros de río asociadas a cerámica campaniforme regional.

formación de esta capa funeraria entre 2620- 2348 cal вс $-1 \sigma-$.

En cuanto al material, se recuperó un bol hemisférico liso no asociado a ninguna inhumación, un adorno formado por ejemplares de dentalia aún fijados entre sí y ocho puntas de flecha con aleta y pedúnculos, elemento bien representado en el Neolítico Final-Calcolítico y el Bronce Inicial. Las puntas tienen un redondeado en los filos $y$, en algún caso, restos de resina del enmangue, lo que hace suponer que no fueron producidas para el enterramiento y que se utilizaron anteriormente (Gibaja et al., 2006).

Después del enterramiento colectivo aparece la UE 5, una unidad con geometría tabular de poca potencia y escasos restos óseos donde se encontraron dos vasos de estilo marítimo. La unidad fue interpretada como una preparación a las posteriores inhumaciones correspondientes a la UE 2. Este segundo episodio de inhumación contenía cuatro individuos, asociados a vasos campaniformes de Estilo Marítimo o Epimarítimo (Francès et al., 2006; 
Olalde et al., 2018). De este tramo de la unidad se realizó una datación radiocarbónica sobre un resto humano -UBAR1061-, destinada a determinar la vigencia del episodio campaniforme internacional del hipogeo (Fig. 5), en 2462$2310 \mathrm{cal} \mathrm{вС-1 \sigma -}$.

\begin{tabular}{|c|c|c|c|c|c|c|}
\hline UE & Tipo de estrato & REFERENCIA & $\begin{array}{c}\text { FECHA } \\
\text { BP }\end{array}$ & $\mathrm{SD}$ & CAL BC I $\sigma$ & CAL BC $2 \sigma$ \\
\hline 15 & N. Final/Calcolítico & UBAR-817 & 4110 & 60 & $2859-2579$ & $2878-2496$ \\
\hline 12 & N. Final/Calcolítico & MAMS-25937 & 3965 & 29 & $2564-2462$ & 2573-2349 \\
\hline 12 & N. Final/Calcolítico & MAMS- 25939 & 3915 & 29 & $2469-2348$ & $2475-2299$ \\
\hline 12 & N. Final/Calcolítico & MAMS- 25940 & 4051 & 28 & $2620-2496$ & $2835-2483$ \\
\hline 2 & C. Epimarítimo & UBAR-1061 & 3890 & 45 & $2462-2310$ & $2476-2207$ \\
\hline 1 & C. Pirenaico & UBAR- 860 & 3870 & 45 & $2456-2292$ & $2469-2206$ \\
\hline
\end{tabular}

Fig. 5. Dataciones radiocarbónicas disponibles del hipogeo del Carrer París (Francès et al., 2006; Olalde et al., 2018).

Inmediatamente encima, y aún dentro de la uE 2, se localizó el tercer episodio de inhumación. Estaba formado por dos esqueletos en mal estado de conservación y solo uno de ellos estaba acompañado por un único bol de fondo plano.

Finalmente, la UE 1 representaría el último episodio de inhumación formado por dos individuos, también en mal estado de conservación y conexiones anatómicas parciales, uno de ellos asociado a un bol liso, y la presencia de un vaso campaniforme regional de Estilo Pirenaico inciso. Los dos cuerpos aparecieron encima de un lecho de guijarros de río, planos y de medidas muy homogéneas.

La preparación de este tipo de elementos no es un hecho desconocido. En Cataluña se encuentran paralelos en los yacimientos de La Bòbila del Casal en Riudecols, Tarragona, con una inhumación sobre un enlosado similar y asociada a material campaniforme (Vilaseca, 1973) y en diversos megalitos del Ne de Cataluña (Tarrús, 2002).

Para este último episodio de inhumación disponemos de una datación por radiocarbono de uno de los huesos de los inhumados -UBAR-860- en 2456-2292 cal вс $-1 \sigma-$, que marca el último uso funerario del hipogeo ${ }^{8}$ contextualizado en el Campaniforme Regional (Fig. 5).

8 Mestres, J.: Datació per radiocarboni de material ossi d'origen humà procedent de l'hipogeu del carrer París de Cerdanyola del Vallès (Vallès Occidental). Informe inédito depositado en 2007 en el Museu d'Història de Sabadell y en Arrago sL Sabadell.

Ediciones Universidad de Salamanca / 요 


\begin{tabular}{|c|c|c|c|c|c|c|}
\hline $\begin{array}{c}\text { UUEE } \\
\text { ConteXto ARQUEOLÓGICO }\end{array}$ & $\begin{array}{l}\text { POTENCIA } \\
\text { MEDIA } \\
(\mathrm{cm})\end{array}$ & Color & FRACCIÓN GRUESA & FRACCIÓN FINA & GeOMetría & $\begin{array}{l}\text { COMPONENTES } \\
\text { ORGÁNICOS E } \\
\text { INORGÁNICOS }\end{array}$ \\
\hline sustrato geológico & - & (5YR 5/7) & $\begin{array}{l}\text { cantos y gravas } \\
\text { subredondeadas }\end{array}$ & $\begin{array}{l}\text { arcillas y limos } \\
\text { arenosos }\end{array}$ & - & - \\
\hline $\begin{array}{c}\text { UE } 19=\text { recorte del } \\
\text { sustrato. Neolítico Final/ } \\
\text { Calcolítico }\end{array}$ & 37 & (5YR 5/4) & $\begin{array}{l}\text { cantos y gravas } \\
\text { subredondeadas }\end{array}$ & $\begin{array}{l}\text { arenas limosas } \\
\text { con arcillas }\end{array}$ & cubeta & cerámica \\
\hline $\begin{array}{l}\text { UE } 18=\text { preparación } \\
\text { de inhumaciones. } \\
\text { Neolítico final/ } \\
\text { Calcolítico }\end{array}$ & 6 & $(7,5$ YR $5 / 1)$ & $\begin{array}{l}\text { gravas y cantos } \\
\text { subredondeados }\end{array}$ & $\begin{array}{l}\text { limos arenosos } \\
\text { con arcillas }\end{array}$ & cubeta & cenizas y carbones \\
\hline $\begin{array}{l}\text { UE } 17 \text { = preparación de } \\
\text { inhumaciones. Neolítico } \\
\text { final/Calcolítico }\end{array}$ & 13 & - & $\begin{array}{l}\text { gravas y cantos } \\
\text { subredondeados }\end{array}$ & arcillas limosas & irregular & cenizas y carbones \\
\hline $\begin{array}{c}\text { UE } 15 \text { Preparación } \\
\text { inhumaciones. Neolítico } \\
\text { final/Calcolítico }\end{array}$ & 13 & - & $\begin{array}{l}\text { cantos y gravas } \\
\text { subredondeadas }\end{array}$ & arcillas limosas & irregular & cenizas y carbones \\
\hline $\begin{array}{c}\text { UE } 12 \text { = inhumaciones } \\
\text { del Neolítico Final/ } \\
\text { Calcolítico }\end{array}$ & 46 & (5YR 6/4) & $\begin{array}{l}\text { gravas y cantos } \\
\text { subredondeados }\end{array}$ & $\begin{array}{l}\text { limos arenosos } \\
\text { con arcillas }\end{array}$ & tabular & $\begin{array}{c}\text { restos óseos } \\
\text { humanos, cerámica, } \\
\text { flechas de sílex }\end{array}$ \\
\hline $\begin{array}{l}\text { UE } 2 \text { = inhumaciones } \\
\text { del Campaniforme } \\
\text { Epimarítimo }\end{array}$ & 36 & (5YR 6/4) & $\begin{array}{l}\text { gravas } \\
\text { subredondeadas }\end{array}$ & $\begin{array}{l}\text { limos arenosos } \\
\text { con arcillas }\end{array}$ & tabular & $\begin{array}{c}\text { restos óseos } \\
\text { humanos y } \\
\text { animales, cerámica } \\
\text { campaniforme }\end{array}$ \\
\hline $\begin{array}{c}\text { UE } 1 \text { = inhumaciones del } \\
\text { Campaniforme } \\
\text { Pirenaico }\end{array}$ & 20 & - & $\begin{array}{l}\text { gravas y cantos } \\
\text { subredondeados }\end{array}$ & $\begin{array}{l}\text { arenas limosas } \\
\text { con arcillas }\end{array}$ & cubeta & $\begin{array}{l}\text { restos óseos } \\
\text { humanos y cerámica } \\
\text { campaniforme }\end{array}$ \\
\hline
\end{tabular}

FIG. 6. Descripción sedimentaria de las distintas unidades identificadas durante la intervención.

-LPP-, polarizada cruzada -LPX- y oblicua incidente-LOI-. También en algunos casos se ha utilizado la microscopía de fluorescencia - BL-. Para su descripción e interpretación se ha seguido a Bullock et al. (1985), Courty et al. (1989), Stoops (2003) y Stoops et al. (2010).

Por último, las calibraciones de las dataciones radiocarbónicas y su análisis bayesiano se han llevado a cabo mediante el software OxCal v.4.3.2 (Bronk Ramsey, 2009) y la curva atmosférica de calibración IntCal'13 (Reimer et al., 2013).

\section{Resultados e interpretación}

\subsection{Análisis micromorfológico}

A continuación se presentan los datos obtenidos del análisis microestratigráfico del hipogeo del Carrer París, según los episodios documentados en la intervención arqueológica, de más antiguo a más reciente. En la tabla que adjuntamos (Fig. 7) aparecen las descripciones micromorfológicas detalladas de las mismas. Las fases documentadas que vamos a analizar a continuación son el sustrato, la preparación constructiva del hipogeo, la preparación para las inhumaciones y las propias inhumaciones.

\subsubsection{Sustrato}

Corresponde al depósito que los constructores del hipogeo recortaron. Según De Más (1983) se trata de un depósito coluvial que descansa sobre un nivel de terraza fluvial del río Sec. Desde el punto de vista microestratigráfico, se trata de un relleno formado mayoritariamente por arcillas limosas con arenas, algunos cantos y gravas subredondeadas y redondeadas. No muestran ordenación alguna ni clasificación. En general, es un depósito heterométrico propio de este tipo de proceso (Bertrán y Texier, 1999; Mücher et al., 2010). El nivel presenta poca porosidad, con huecos de tipo cavitario y canales atribuidos principalmente a la acción de las raíces. 


\begin{tabular}{|c|c|c|c|c|c|}
\hline $\begin{array}{c}\text { UE/ } \\
\text { Muestra }\end{array}$ & $\begin{array}{c}\text { Micro } \\
\text { ESTRUCTURA }\end{array}$ & POROSIDAD & MASA BASAL & $\begin{array}{l}\text { COMPONENTES } \\
\text { ORGÁNICOS E } \\
\text { INORGÁNICOS }\end{array}$ & $\begin{array}{c}\text { EDAFORRASGOS Y } \\
\text { ACTIVIDAD BIOLÓGICA }\end{array}$ \\
\hline $\begin{array}{l}\text { sustrato } \\
\text { M1 }\end{array}$ & $\begin{array}{l}\text { cavitaria/ } \\
\text { canales }\end{array}$ & $\begin{array}{l}15 \% \\
\text { cavidades, huecos de } \\
\text { empaquetamiento } \\
\text { compuesto }\end{array}$ & $\begin{array}{l}\mathrm{G} / \mathrm{f} 50 \mu \mathrm{m}: 1 / 6 . \\
\text { arcillas limosas y arenas } \\
\text { gravas subangulosas }\end{array}$ & & $\begin{array}{l}\text { +++ hipo-revestimientos de } \mathrm{CaCO}_{3 ;} \\
\text { ++ nódulos órticos de } \mathrm{CaCO}_{3} ; \\
\text { + colgantes } \mathrm{CaCO} ; \\
\text { óxidos (hidróx.) de } \mathrm{Fe}_{\text {; }}+\text { rev./hipo- } \\
\text { revestimientos de material fino. } \\
\text { raíces; + agregados de fauna del' suelo }\end{array}$ \\
\hline $\begin{array}{l}\text { UE } 19 \\
\text { M7 inf. }\end{array}$ & $\begin{array}{l}\text { cavitaria/ } \\
\text { fisuras. } \\
\text { Zonas } \\
\text { granular }\end{array}$ & $\begin{array}{l}25-35 \% \\
\text { cavidades, } \\
\text { canales, huecos de } \\
\text { empaquetamiento } \\
\text { compuesto }\end{array}$ & $\begin{array}{l}\mathrm{G} / \mathrm{f} 50 \mu \mathrm{m}: 1 / 5 \text {; arcillas } \\
\text { arenosas, } \\
\text { gravas subangulosas y } \\
\text { cantos subredondeados }\end{array}$ & ** malacología & $\begin{array}{l}\text { +++ queras; ++ recristalizaciones y } \\
\text { disoluciones de } \mathrm{CaCO}_{33} \\
\text { + revestimientos de } \mathrm{CaCO}_{3} ; \\
\text { + costras de } \mathrm{CaCO} \mathrm{CO}_{3} ; \\
\text { + nódulos disórticos de } \mathrm{CaCO}_{3} ; \\
\text { + rev. e hipo-revestimientos de material } \\
\text { fino; + nódulos de óxidos (hidróx.) de } \\
\text { Fe; +++ raíces; ++ agregados de fauna } \\
\text { del suelo; ++ calcita biogénica }\end{array}$ \\
\hline $\begin{array}{l}\text { UE } 18 \\
\text { M5 inf. }\end{array}$ & $\begin{array}{l}\text { cavitaria/ } \\
\text { canales }\end{array}$ & $\begin{array}{l}15-20 \% \\
\text { cámaras, huecos de } \\
\text { empaquetamiento } \\
\text { compuesto }\end{array}$ & $\begin{array}{l}\mathrm{G} / \mathrm{f} 50 \mu \mathrm{m}: 1 / 3 \\
\text { limos, arenoso y arcillas; } \\
\text { gravas y cantos } \\
\text { subredondeados }\end{array}$ & $\begin{array}{l}* \text { carbones; } \\
\text { * cenizas } \\
\text { (pseudomorfos } \\
\text { romboidales de } \\
\mathrm{CaCO}_{3} \text { ) } \\
\end{array}$ & $\begin{array}{l}+++ \text { rev. e hipo-revestimientos de } \\
\text { material fino, ++ revestimientos de } \\
\mathrm{CaCO}_{3} \text {; + óxidos (hidróx.) de Fe; ++ } \\
\text { raíces }\end{array}$ \\
\hline $\begin{array}{l}\text { UE } 17 \\
\text { M7 sup., } \\
\text { M5 sup. y } \\
\text { M4 inf. }\end{array}$ & $\begin{array}{l}\text { cavitaria/ } \\
\text { granular }\end{array}$ & $\begin{array}{l}25-30 \% \\
\text { huecos de } \\
\text { empaquetamiento } \\
\text { compuesto, cavidades, } \\
\text { canales y vesículas } \\
\end{array}$ & $\begin{array}{l}\mathrm{G} / \mathrm{f} 50 \mu \mathrm{m}: 1 / 4 ; \\
\text { limos arenosos y } \\
\text { arcillas; gravas y cantos } \\
\text { subredondeados }\end{array}$ & $\begin{array}{l}\text { * carbón; } \\
\text { * huesos }\end{array}$ & $\begin{array}{l}\text { +++ queras; ++ colgantes } \mathrm{CaCO}_{3} ; \\
\text { + nódulos de óx. (hidróx.) de } \mathrm{Fe} \\
\text { + hipo-revestimientos de fosfato; ++ } \\
\text { raíces; + agregados de fauna del suelo }\end{array}$ \\
\hline $\begin{array}{l}\text { UE } 15 \\
\text { M6 inf. }\end{array}$ & $\begin{array}{l}\text { cavitaria/ } \\
\text { canales. } \\
\text { Zonas } \\
\text { granular }\end{array}$ & $\begin{array}{l}25-30 \% \text { cavidades, } \\
\text { cámaras, huecos de } \\
\text { empaquetamiento } \\
\text { compuesto y canales }\end{array}$ & $\begin{array}{l}\text { G/f } 50 \mu \mathrm{m}: 1 / 3 ; \\
\text { limos, arenosos y } \\
\text { arcillas; cantos de } \\
\text { morfología redondeada, } \\
\text { algunas con trazas de } \\
\text { rubefacción y gravas } \\
\text { subredondeadas }\end{array}$ & $\begin{array}{l}\text { ** carbones; } \\
\text { * cenizas } \\
\text { (pseudomorfos } \\
\text { de } \mathrm{CACO}_{3} \text { ); } \\
\text { * malacología; } \\
\text { * huesos }\end{array}$ & $\begin{array}{l}\text { ++ rev. hipo-revestimientos de material } \\
\text { fino; ++ Ox. (hidróx.) de Fe; + } \\
\text { colgantes } \mathrm{CaCO},+ \text { queras; + hipo- } \\
\text { revestimientos de fosfato; ++ raíces }\end{array}$ \\
\hline $\begin{array}{l}\text { UE } 12 \\
\text { M6 sup. y } \\
\text { m4 }\end{array}$ & $\begin{array}{l}\text { canales/ } \\
\text { granular. } \\
\text { M4. Cavitaria }\end{array}$ & $\begin{array}{l}20-25 \% \\
\text { canales, cámaras, } \\
\text { cavidades y huecos } \\
\text { de empaquetamiento } \\
\text { compuesto }\end{array}$ & \begin{tabular}{|l|}
$\mathrm{G} / \mathrm{f} 50 \mu \mathrm{m}: 1 / 5$; limos, \\
arenosos y arcillas. \\
Gravas y cantos \\
subredondeados. Costras \\
sedimentarias de débil \\
potencia $(<70 \mu \mathrm{m})$
\end{tabular} & $\begin{array}{l}\text { * carbones; } \\
\text { ** huesos }\end{array}$ & $\begin{array}{l}\text { +++ queras; ++ rev. e hipo- } \\
\text { revestimientos de material fino; ++ óx. } \\
\text { (hidróx.) de Fe; ++ hipo-revestimientos } \\
\text { de fosfato; ++ nódulos de fosfato } \\
\text { cristalítico; ++ raíces; + agregados de } \\
\text { fauna del suelo }\end{array}$ \\
\hline $\begin{array}{l}\text { UE } 2 \\
\text { M2 y m3 } \\
\text { inf. }\end{array}$ & $\begin{array}{l}\text { cavitaria/ } \\
\text { canales. } \\
\text { Zona } \\
\text { granular }\end{array}$ & $\begin{array}{l}20-25 \% \\
\text { cavidades, } \\
\text { canales, huecos de } \\
\text { empaquetamiento } \\
\text { compuesto }\end{array}$ & $\begin{array}{l}\mathrm{G} / \mathrm{f} 50 \mu \mathrm{m}: 1 / 4 \\
\text { limos, arenosos } \\
\text { y arcillas; gravas } \\
\text { redondeadas y } \\
\text { subredondeadas; } \\
\text { costras sedimentarias } \\
\end{array}$ & $\begin{array}{l}\text { * carbones; } \\
\text { * huesos; } \\
\text { * malacología }\end{array}$ & $\begin{array}{l}\text { ++ rev. e hipo-revestimientos } \\
\text { de material fino; ++ rev. e hipo- } \\
\text { revestimientos de fosfato; ++ nódulos } \\
\text { de fosfato; +Óx. e (hidróx.) de Fe; } \\
\text { + hipo-revestimientos } \mathrm{CaCO}_{3} \text {; +++ } \\
\text { agregados de fauna del suelo; + raíces } \\
\end{array}$ \\
\hline $\begin{array}{l}\text { UE } 1 \\
\text { M3 sup. }\end{array}$ & $\begin{array}{l}\text { sub-angular } \\
\text { débil/ } \\
\text { granular }\end{array}$ & $\begin{array}{l}35-40 \% \\
\text { canales, fisuras con } \\
\text { caras parcialmente } \\
\text { acomodadas, huecos } \\
\text { de empaquetamiento } \\
\text { compuesto } \\
\end{array}$ & $\begin{array}{l}\mathrm{G} / \mathrm{f} 50 \mu \mathrm{m}: 1 / 4 \\
\text { limos, arcillosos y } \\
\text { arenas; gravas y cantos } \\
\text { subredondeadas; } \\
\text { costras sedimentarias } \\
(600-1200 \mu \mathrm{m}) \\
\end{array}$ & $\begin{array}{l}\text { *microcarbones; } \\
\text { * malacología } \\
\text { (gasterópodos); * } \\
\text { huesos. }\end{array}$ & $\begin{array}{l}\text { ++ rev. e hipo-restimientos de arcillas } \\
\text { con líneas de extinción difusas; + rev. e } \\
\text { hipo-revestimiento de } \mathrm{CaCO}_{3} ;+ \text { Óx. } \\
\text { e (hidróx.) de Fe; +++ raíces, ++ calcita } \\
\text { biogénica }\end{array}$ \\
\hline
\end{tabular}

Fig. 7. Descripción micromorfológica de las unidades estratigráficas muestreadas. La mineralogía y litología de todas las unidades está compuesta principalmente por cuarzo, calcita, calcáreas, cuarcita, arenisca y esquisto. La distribución relacionada de todas las unidades es porfirica de espaciado simple con fábrica de birrefringencia cristalítica y calcítica. Clasificación de frecuencias (Bullock et al., 1985): * muy poco (<5\%); ** poco (5-15\%); *** presente (15-30\%); **** frecuente (30-50\%); **** dominante (50-70\%); ${ }^{* * * * *}$ muy dominante (>70\%). Clasificación de abundancia de edaforrasgos (Bullock et al., 1985): + raro (<2\%); ++ ocasional (2-5\%); +++ muchos (5-10\%); ++++ abundante (10-20\%); +++++ muy abundante (>20\%). 
Como rasgos edáficos aparecen importantes acumulaciones de $\mathrm{CaCO}_{3}$ : hipo-revestimientos de tamańo micrítico en los poros, colgantes - pendentsen la base del material detrítico (Fig. 8А у в), principalmente en cantos y gravas, y también en forma de nódulos formados in situ, denominados órticos y costras. Uno de los rasgos que destacamos son los colgantes, cuya génesis estaría relacionada con procesos de disolución y precipitación de carbonatos, que se acentúa en la parte inferior del material detrítico, ya que se ha retenido mayor humedad (Dorronsoro, 2020; Ducloux y Laouina, 1989; Durand et al., 2010). Algunos colgantes están formados por diferentes capas de $\mathrm{CaCO}_{3}$, relacionando su génesis a diferentes condiciones ambientales. Las primeras, más claras, representadas por cristales fibrosos en forma de aguja tipo listón, se formarían en fases más secas con menor actividad biológica; las segundas, propias de fases más húmedas, son más oscuras y están formadas por cristales de forma romboédrica, más pequeños que los anteriores, dispuestos de manera heterogénea y con más material detrítico -limos y arenas finas- (Durand et al., 2010).

\subsubsection{Preparación constructiva del hipogeo}

Una vez recortado el sustrato geológico se llevaron a cabo las primeras adecuaciones de la estructura para depositar las futuras inhumaciones. La primera es la UE 19, formada por arcillas arenosas como fracción mayoritaria. Los cantos y gravas aparecen con rasgos similares a la unidad anteriormente descrita. También se observan procesos de carbonatación entre los cuales destacamos los revestimientos en la parte superior o en los laterales del material detrítico (Fig. 8c y D), con una morfología que concuerda con los colgantes del sustrato, pero difiriendo solo en la posición donde se forman. Así como la aparición de los nódulos de $\mathrm{CaCO}_{3}$, de tipo disórtico, indicadores de haber sufrido una translocación local (Wieder y Yaalon, 1974), que tienen una morfología redondeada y un cambio de orientación vertical o inclinada. Sus límites son netos y generalmente presentan fisuras a su alrededor, separando el nódulo del material que les rodea. Estos dos edaforrasgos irán apareciendo de forma recurrente en las siguientes unidades.

Finalmente se localiza otro rasgo edáfico asociado a carbonato biogénico, las queras (Fig. 8E). Se trata de canales rellenos por cristales esparíticos equigranulares, propios de un proceso de calcificación-descalcificación específico asociado a la impregnación de los tejidos de las raíces y observado frecuentemente en suelos calcáreos semiáridos. Para su formación, es necesaria una estabilidad del suelo (Herrero y Porta, 1987; Durand et al., 2010).

La porosidad de la unidad está condicionada, en gran parte, por la actividad biológica de las raíces, que crea los huecos de canal, y de la fauna de suelo, detectada por la presencia de zonas con una microestructura granular (Bergadà, 1993; Morrás, 2015). También se localizan gránulos de calcita biogénica excretada por lombrices. Estos aparecen formando agregados de cristales de calcita individuales y dispuestos en un patrón radial (Fig. 8F) (Canti y Piearce, 2003; Canti, 2007). La fuerte actividad biológica en esta unidad indica una evolución edáfica.

\subsubsection{Preparación para la deposición de las inhumaciones}

Está formada por las uUEe 18, 17 y 15. Las tres presentan una microestructura cavitaria con dominio de la fracción fina, formada por limos arenosos y arcillas. Hay un aumento de la fracción gruesa compuesta por gravas y algunos cantos de morfología subredondeada de igual litología que en las anteriores unidades. Su disposición en la masa basal es muy heterogénea en forma, tamaño $y$ frecuencia.

La principal característica de las tres unidades estratigráficas es la presencia de rasgos asociados a combustiones. En especial aparecen microcarbones y carbones que se distinguen por tener grandes poros elípticos concentrados de forma radial, propia de maderas duras de anillos porosos (Canti, 2017).

En la UE 18 se puede apreciar también una acumulación de carbones, que se extiende horizontalmente, asociada a residuos de cenizas vegetales 

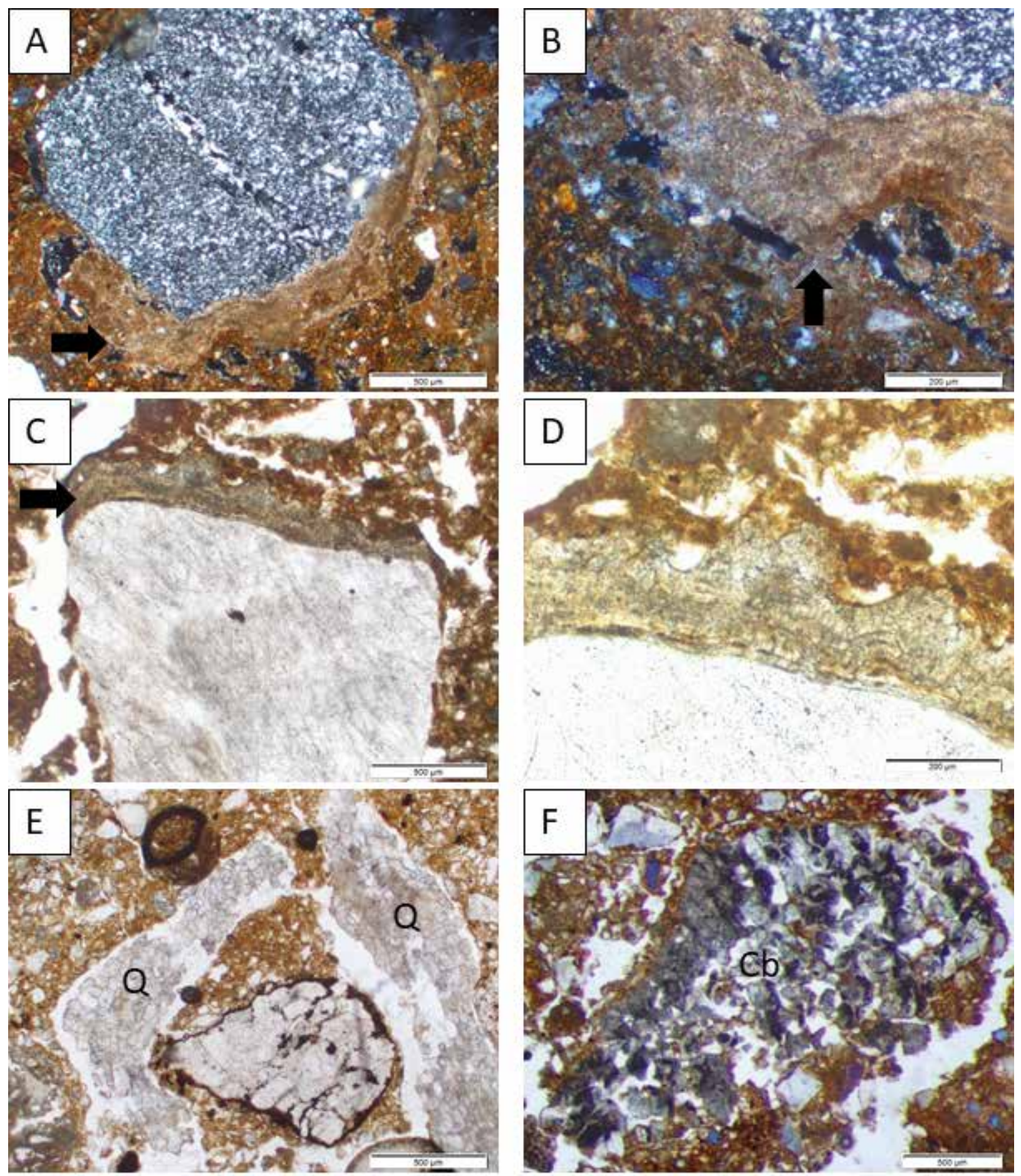

FIG. 8. A) acumulación de $\mathrm{CaCO}_{3}$ in situ-colgante-, en $\left.L P X ; B\right)$ detalle del colgante-flecha-de la imagen anterior, en LPX; C) revestimiento de $\mathrm{CaCO}_{3}$ en el techo -flecha-, situación no habitual de este edaforrasgo-UE 18-, en LPP; D) detalle del revestimiento de la imagen anterior, en $L P P$; E) Queras -Q- rellenando dos canales por cristales esparíticos equigranulares -UE 19-; LPP; F) calcita biogénica-Cb-excretada por lombrices formando agregados de cristales de calcita individual y dispuesta en un patrón radial -UE 19-, en LPP. 
leñosas, caracterizadas por pseudomorfos romboidales de carbonato de calcio (Canti, 2003). Algunos de estos carbones se localizan formando parte de laminaciones de arenas finas a limo arcillosas con cierta clasificación. También encontramos fragmentos de hueso que presentan fisuras y una coloración fuertemente anaranjada en LPP y cierta birrefringencia en LPX, indicando una temperatura de combustión alrededor de los $300{ }^{\circ} \mathrm{C}$ (Bergadà, 1998; Villagrán et al., 2017).

En la ue 15 se localiza un área de combustión constituida por una acumulación de carbones sobre un soporte detrítico con nódulos e impregnaciones de óxidos e hidróxidos de Fe (Fig. 9A у в), lo que denota rasgos de termoalteración de la masa basal (Mentzer, 2014; Mallol et al., 2017). También aparecen de forma dispersa otros elementos resultantes de combustiones, como carbones, gravas con trazas de óxidos e hidróxidos de $\mathrm{Fe}$, huesos con coloraciones anaranjadas/marrones en LPP, propias de una combustión a $400-450{ }^{\circ} \mathrm{C}$ o de color amarillo-marrón pálido en LPP, gris de orden bajo en LPX con numerosas fisuras, trazas que reflejan temperaturas superiores (Bergadà, 1998; Villagrán et al., 2017).
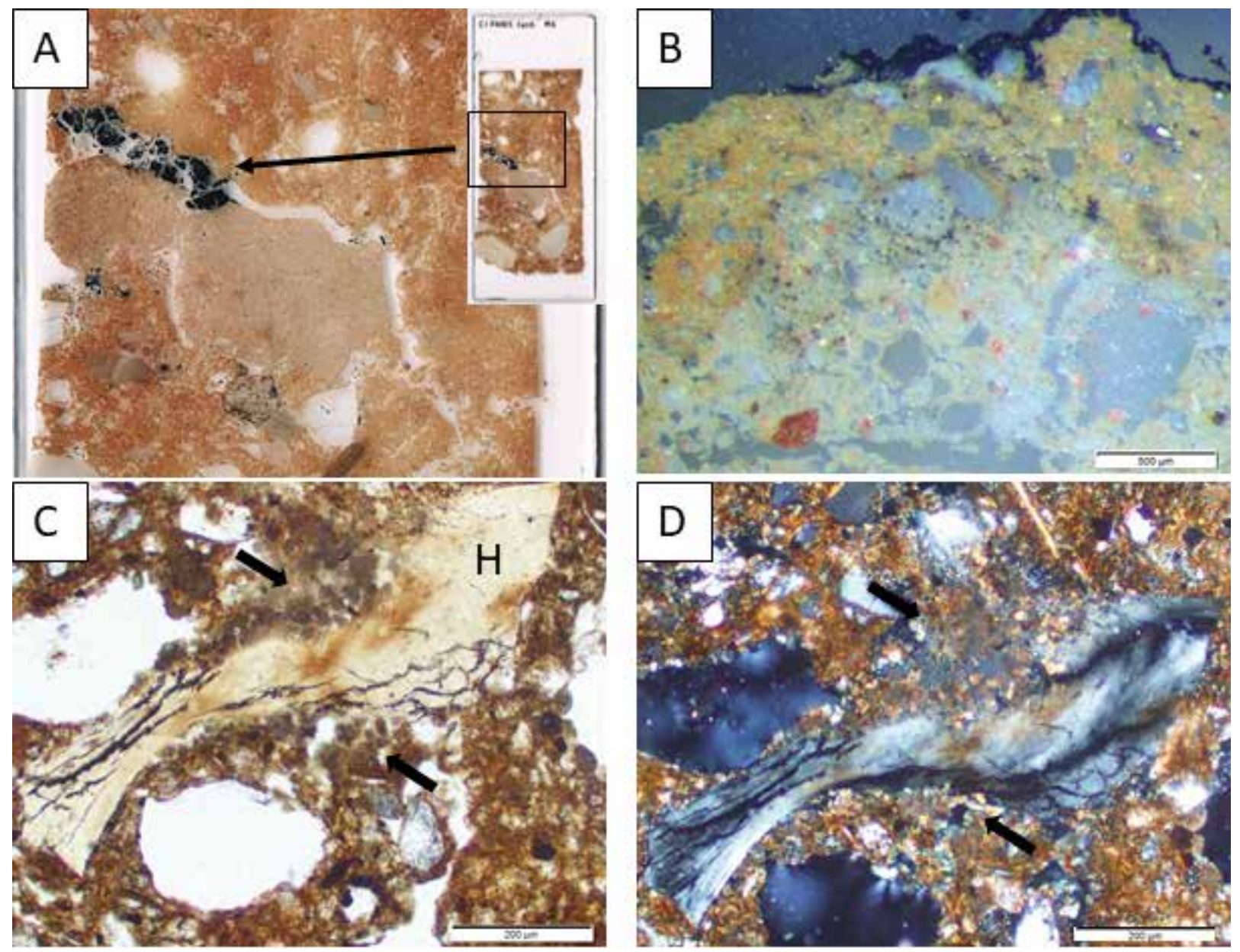

FIG. 9. A) detalle de la acumulación de carbones -UE 15- de la lámina M6; B) soporte de los carbones de la imagen anterior; el material detrítico denota rasgos de termoalteración de la masa basal-nódulos e impregnaciones de óxidos e hidróxidos de $\mathrm{Fe}$. LOI; C) fragmento de hueso - $H$-de color amarillo-marrón pálido, numerosas fisuras y cenizas vegetales leñosas adheridas - agregados de pseudomorfos de calcita señalados por las flechas-, en LPP; D) lo mismo en LPX. 

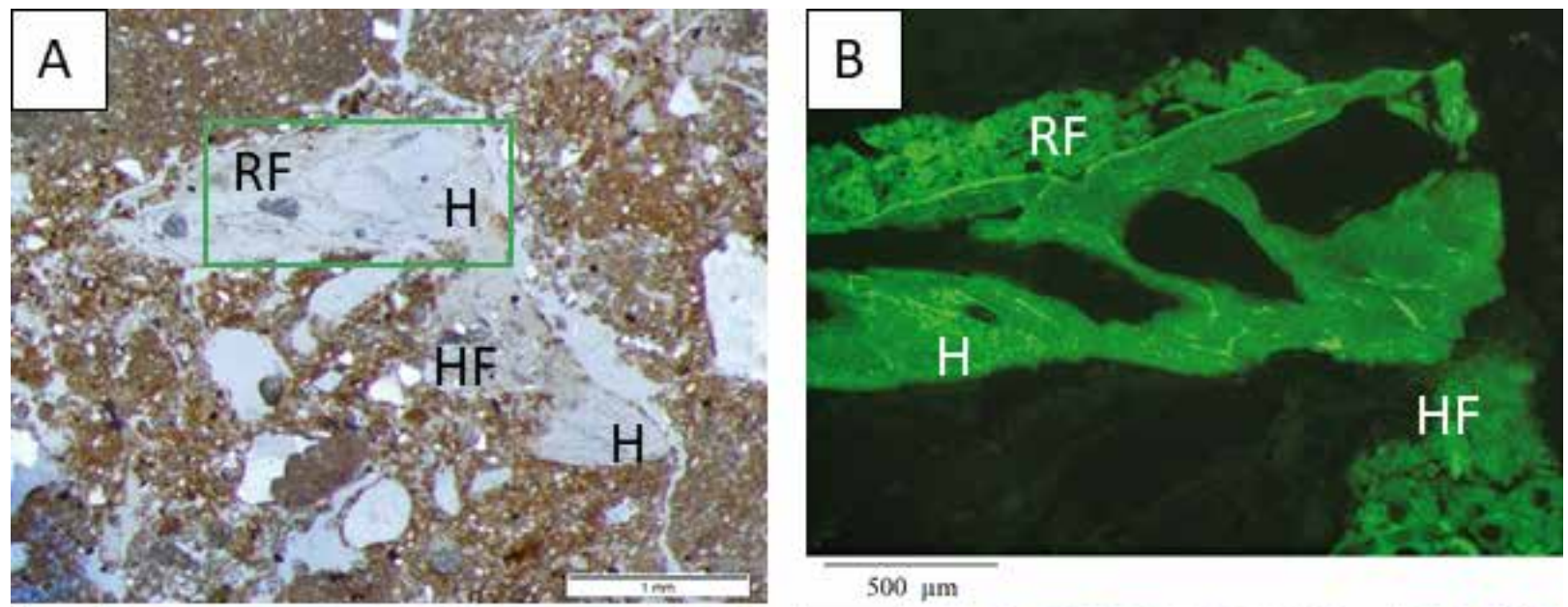

$500 \mu \mathrm{m}$
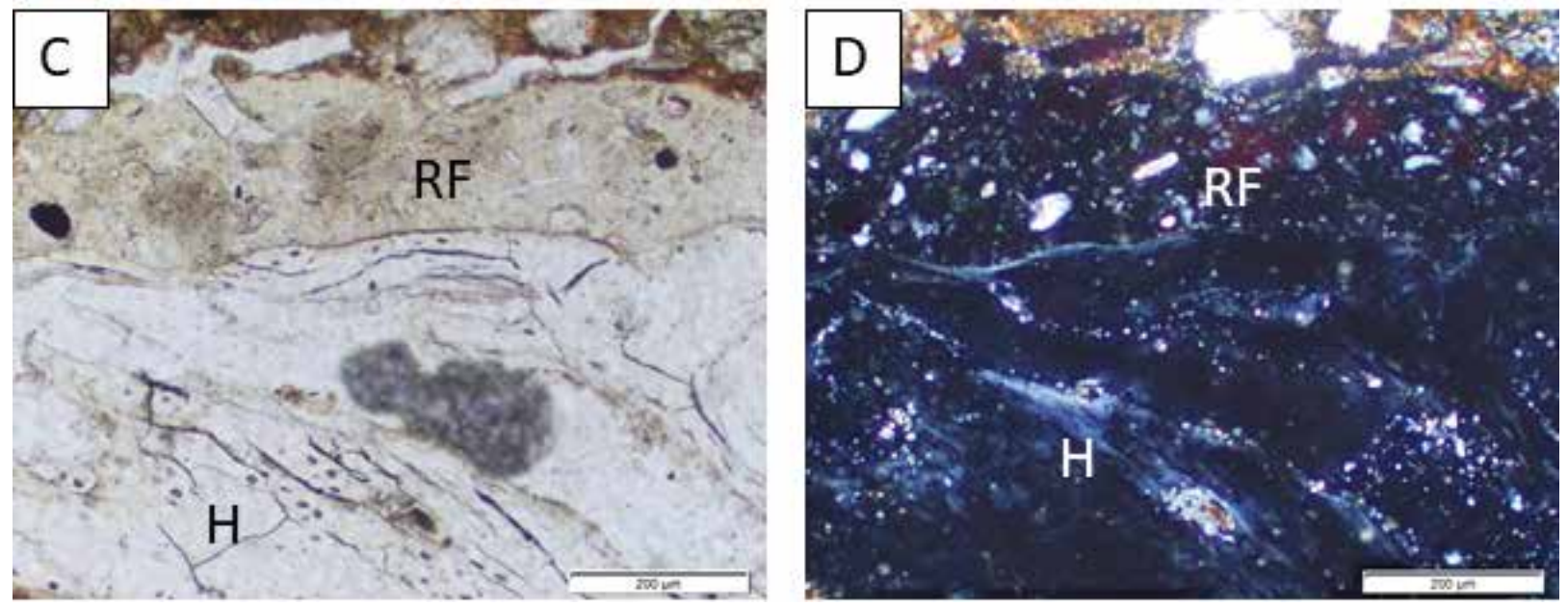

FIG. 10. Hueso asociado a hipo-revestimientos y revestimientos de fosfato en la UE 2: A) vista general de un fragmento óseo-H-con revestimiento $-R F$ - e hipo-revestimiento $-H F$ - amarillo criptocristalino de fosfato en $L P P$; $B$ ) detalle del recuadro en verde en BL. Nótese la fluorescencia del revestimiento/hipo-revestimiento de fosfato en el fragmento óseo; C) detalle del revestimiento criptocristalino en el hueso en LPP; D) lo mismo en LPX.

En algún caso estos huesos presentan cenizas vegetales leñosas adheridas (Fig. 9c y D). Finalmente, en la UE 17 se localizan gravas con diversas fisuras atribuidas también a la acción del fuego (Mentzer, 2014).

\subsubsection{Inhumaciones}

El primer episodio de inhumación -Neolítico Final- se encuentra íntegramente en la UE 12, la cual presenta una microestructura cavitaria y de canales formada en gran parte por las raíces. Domina la fracción detrítica de limos arenosos y arcillas con escasa presencia de gravas. No se aprecia clasificación del material detrítico.

En este momento destaca la presencia de diversas costras sedimentarias que son de poco grosor y están formadas por limos arcillosos. Serían producidas por el arrastre de material fino de circulaciones hídricas de muy débil intensidad. Por otra parte, también aparecen revestimientos de material fino, principalmente arcilloso, en el material detrítico.

Los fragmentos de huesos encontrados, muy presumiblemente humanos, muestran una morfología subredondeada, color blanco pálido en LPP y cierta 
birrefringencia en LPX. En ellos vemos numerosas fisuras y un aumento de la porosidad, en algunos casos muy acusada. Estas características son resultado, en mayor o menor grado, de la pérdida del compuesto órgano-mineral que lo forma, propio de trazas de disolución (Hedges y Millard, 1995). Estos huesos están asociados a hipo-revestimientos criptocristalinos de fosfato, así como nódulos autigénicos criptocristalinos de fosfato en la masa basal.

El segundo y tercer momento de inhumación -Campaniforme Internacional- se localizaron en la UE 2. Esta presenta similitud con la primera fase de inhumación por lo que respecta a la porosidad, microestructura y masa basal, pero con un ligero aumento de cantos, algunos con fisuras y orificios originados por procesos de disolución. Los restos óseos continúan la morfología redondeada de los mismos y su color blanquecino en LPP, así como su asociación a hipo-revestimientos y revestimientos amarillos criptocristalinos de fosfato (Fig. 10), rellenos en algún hueco y nódulos autigénicos de fosfato. Como en la UE 12, se localizan débiles costras sedimentarias (Fig. 11A), también formadas por arroyadas difusas, y encontramos hipo-revestimientos
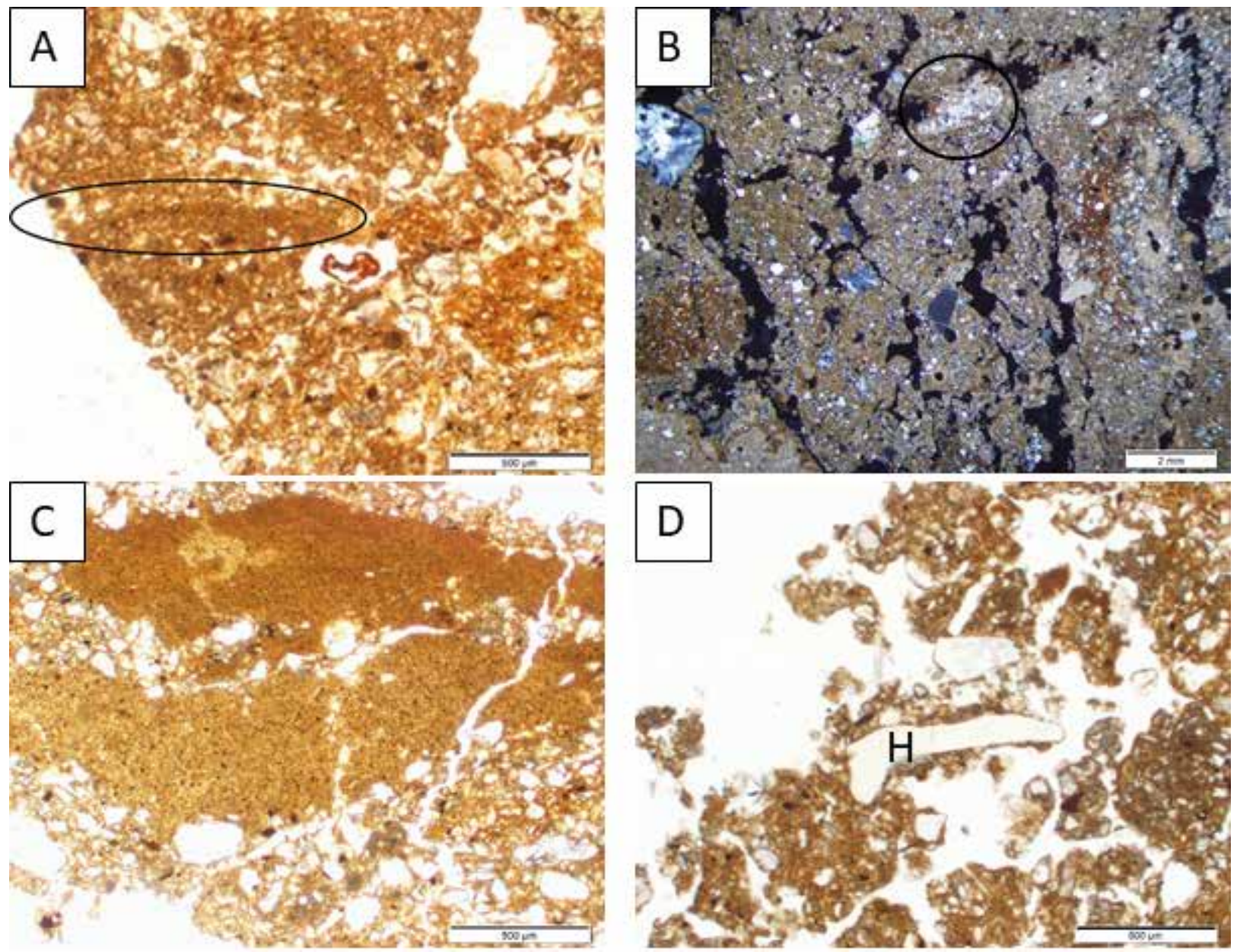

FIG. 11. A) costra sedimentaria -elipse-formada en la UE 2 debido a arroyadas difusas, en LPP; B) microestructura de bloques subangulares $-U E$ 1- donde se puede ver también un agregado de calcita biogénica de lombrices-círculo-, en LPX; C) costra sedimentaria en la UE 1 con importante grosor-1200 $\mu \mathrm{m}$-granoclasificada, en LPP; D) huesos con una morfología muy redondeada $-H-$, limites muy netos y sin estar asociados a fosfatizaciones en la UE 1 , en LPP. 
calcíticos en huecos como resultado de la precipitación del carbonato cálcico debido al metabolismo de las raíces (Durand et al., 2010).

En la UE 1 -Campaniforme Regional- localizamos el último episodio de inhumación. Esta unidad está dominada por limos arcillosos con arenas $\mathrm{y}$ algunas gravas subredondeadas. Muestra la mayor porosidad de todas las muestras $-35-40 \%-$, formada en gran parte por canales y huecos de empaquetamiento compuesto. La microestructura es de bloques subangulares (Fig. 11B), indicadora de procesos de humectación-desecación de la matriz (Fitzpatrick, 1990; Morrás, 2015), y en algunos sectores granular.

Destaca sobremanera la presencia de importantes costras sedimentarias granoclasificadas -600 a $1200 \mu \mathrm{m}$ de grosor- formadas como resultado del transporte lateral de las partículas finas de la superficie por el agua (Fig. 11c).

Entre los elementos antrópicos han aparecido de forma dispersa algunos fragmentos de hueso y de carbón. Los huesos, aunque escasos, presentan rasgos distintos con una morfología redondeada y límites muy netos (Fig. 11D). Por otra parte, se localizan indicios de una importante actividad biológica -restos de raíces, hipo-revestimientos calcíticos en huecos-, agregados de calcita biogénica de lombrices y zonas con microestructura granular- y de infiltración de circulaciones hídricas -revestimientos de arcillas limosas no laminados en huecos.

\subsection{Dataciones: análisis bayesiano}

Se ha considerado interesante añadir el análisis bayesiano con el fin de contextualizar las diferentes fases de uso del hipogeo. En el análisis bayesiano se ha obviado la fecha sobre carbón de la UE 15, a causa del tipo de muestra y, por tanto, se ha realizado sobre tres fases, con unos índices óptimos $-\mathrm{A}_{\text {model }}=$ 113.3; $\mathrm{A}_{\text {overall }}=112.4-$ (Fig. 12). Por tanto, después de los niveles anteriores a la primera fase funeraria de la estructura, la primera capa de inhumaciones, del Neolítico Final-Calcolítico -UE 12-, se empezó a formar c. $2570 \mathrm{cal}$ вс con una representatividad máxima entre 2520-2439 cal $\mathrm{BC}-1 \sigma-$. Posteriormente, a través de una transición de no más de 60 años, el primer episodio campaniforme -UE 2- se

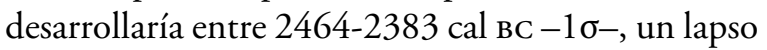
parcialmente solapado al de la capa de inhumaciones del Campaniforme Regional -uE 1-, entre 24322296 cal вС -10-, que marcaría el final de uso del hipogeo. Estos datos indicarían que, sin poder incluir los niveles basales de la estructura -UE 15-, las inhumaciones de la capa del Neolítico Final-Calcolítico y las asociadas al Campaniforme Internacional y Regional se desarrollarían a lo largo de 250-200 años. Sin embargo, no se puede diferenciar con claridad la transición entre el uso en el hipogeo de las cerámicas campaniformes internacionales y el de las regionales, situación muy parecida a la que nos encontramos en el NE de la Península Ibérica (Soriano, 2017).

\section{Discusión}

El análisis micromorfológico del hipogeo del Carrer París ofrece algunos resultados concernientes a los principales agentes que han intervenido en el relleno arqueosedimentario del yacimiento, aportando datos significativos que pueden contribuir a la interpretación general del mundo funerario del Neolítico Final y del Calcolítico Campaniforme en el NE Peninsular. Se presenta la discusión de los resultados en dos apartados: el primero, referente a la construcción y adecuación del hipogeo para realizar las inhumaciones y el segundo, concerniente al registro funerario.

\subsection{Construcción del hipogeo}

La UE 19 es la primera unidad y respondería a la adecuación inicial del hipogeo para el depósito de las inhumaciones. Está formada por el mismo tipo de material detrítico que el sustrato, aunque se observan algunos rasgos distintivos, referidos a las acumulaciones de $\mathrm{CaCO}_{3}$ que aparecen removilizadas, como serían los nódulos disórticos y los 
OxCal v4.3.2 Bronk Ramsey (2017); r:5 IntCal13 atmospheric curve (Reimer et al 2013)

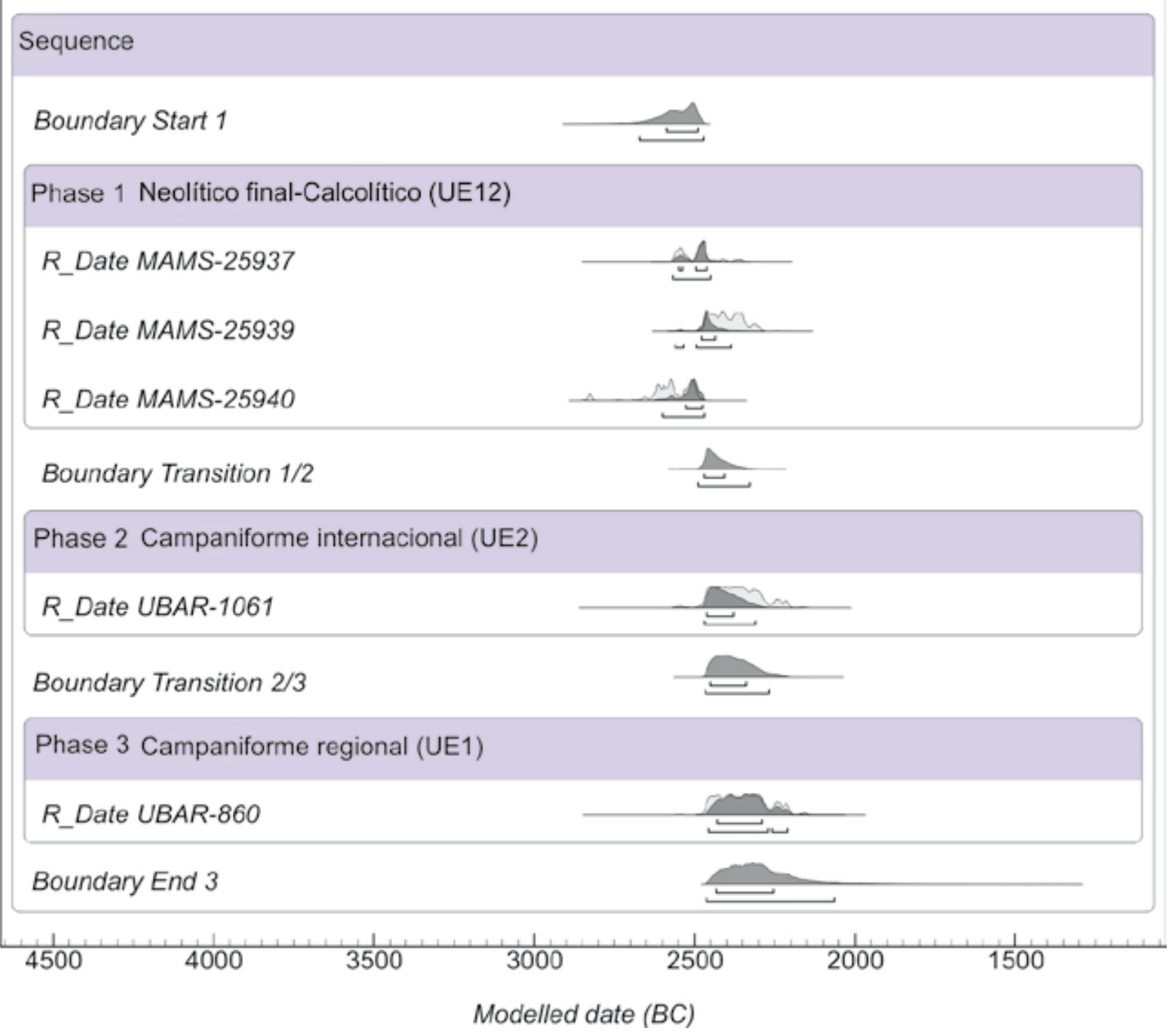

Fig. 12. Análisis bayesiano de las fases del hipogeo del Carrer París.

revestimientos de $\mathrm{CaCO}_{3}$ fuera de su posición habitual. Estos rasgos nos hacen plantear que la UE 19 fue un recorte relleno de material excavado del propio hipogeo como preparación previa para depositar a los inhumados.

Otro aspecto importante de esta unidad es la elevada presencia de rasgos edáficos, hecho inusual en el interior de un hipogeo. La ubicación de la muestra en el lugar donde la intervención arqueológica determinó la entrada (cf. 2.2 y Fig. 3) facilita su exposición a la luz en ausencia de un sistema de cierre anterior a su uso. Este hecho explicaría la formación de queras -raíces- y actividad de la fauna del suelo - porosidad, microestructura granular y agregados de calcita biogénica- que presenta la UE 19. Todo esto nos sugiere que esta unidad probablemente permaneció un periodo de tiempo en superficie para la formación de dichos rasgos. Por esta razón, interpretamos que el hipogeo fue planificado y construido con antelación a la primera inhumación. 
La secuencia continúa en las uUEe 18, 17 y 15 con similares rasgos edafosedimentarios a la UE 19. Por tanto, nos planteamos el mismo origen, salvo que en estas unidades hay un aumento de la fracción de cantos, quizás debido a una selección del material para ofrecer un mejor soporte a las primeras inhumaciones. El elemento distintivo de estas unidades es la abundante presencia de restos carbonosos de maderas duras. Este rasgo es coincidente con el estudio antracológico realizado de la UE 15 , en el cual la mayor parte pertenecían al roble (Francès et al., 2006). Desde el punto de vista microestratigráfico, en la UE 15 dichos fragmentos aparecen asociados a un soporte rubefactado, lo que nos hace plantear que la combustión fue in situ (Mentzer, 2014). De todos modos, también aparecen fragmentos cenicientos, carbones, cantos con fisuras, así como gravas y huesos con trazas de termoalteraciones dispersos en la matriz. Todo ello nos indica una cierta remoción de las combustiones (Miller et al., 2009), ayudada por la entrada al hipogeo de circulaciones hídricas, como atestiguan las laminaciones de arenas finas a limo arcillosas (Pagliai y Stoops, 2010).

Así pues, antes del depósito de las primeras inhumaciones se realizaron hogares en el interior del hipogeo. Quizás dichas combustiones estarían relacionadas con algún tipo de ritual, probablemente para consagrar el hipogeo antes de su uso como recinto funerario. En la vertiente mediterránea peninsular han aparecido diversos yacimientos del Neolítico Final-Calcolítico donde se ha propuesto la realización de rituales a los difuntos. Es el caso del hipogeo calcolítico de Camino del Molino, en Caravaca de la Cruz, Murcia, donde la base de la estructura funeraria presentaba diversas estructuras de combustión y un nivel carbonoso que ocupaba buena parte del espacio (Lomba et al., 2009); la Cova de Can Sadurní, en Begues, Barcelona, donde se encontraron tres estructuras de combustión sincrónicas al uso funerario con restos de ovicaprinos consumidos, o en el hipogeo de Costa de Can Martorell, en Dosrius, Barcelona, donde también se propuso la realización de banquetes funerarios (Soriano, 2017). Por consiguiente, los fragmentos de huesos quemados del hipogeo podrían ser indicativos de dicha actividad. Una vez realizado el ritual, se habrían removido dichos restos quedando esparcidos junto a material no quemado. Este proceso de remoción, antrópica y también por circulaciones hídricas de débil intensidad, explicaría la dificultad para determinar, durante las intervenciones de campo, si las combustiones fueron efectuadas en el interior del hipogeo (Francès et al., 2006).

\subsection{Registro funerario}

Comprende cuatro episodios de inhumación: uno localizado en la UE 12, correspondiente al Neolítico Final, y otros tres, en las uUee 2 y 1, correspondientes al Calcolítico Campaniforme. Hemos decidido agruparlas a nivel microestratigráfico, ya que aparecen rasgos similares en cuanto a su génesis.

El relleno sedimentario de estas unidades responde principalmente a la progresiva disgregación de la cubierta y de las paredes del sepulcro. El material que rellena las unidades presenta las mismas características que las del sustrato, con la presencia de arroyadas difusas dando lugar a costras sedimentarias. Estas se forman por la entrada de agua en el hipogeo, muy probablemente de lluvia, que arrastra material fino y lo deposita en la superficie del suelo. La capacidad del suelo para absorver agua y el arrastre del material fino dependen de varios factores; por ejemplo, de si hay cubierta vegetal que la absorba; de la textura del suelo -rocoso, arenoso o arcilloso-; o de su saturación de agua previa a la lluvia (Goldberg y Macphail, 2006). Su aparición de forma regular a lo largo de las diferentes unidades estratigráficas indica que los diferentes inhumados -tanto los más antiguos como los asociados al Campaniforme- no fueron sepultados, sino que los cadáveres fueron simplemente depositados en el hipogeo, sin otra cobertura que alguna mortaja o contenedor, como demuestra la posición marcadamente replegada de alguno de los cuerpos de la UE 2. La progresiva disgregación del hipogeo y los episodios de arroyadas fueron cubriendo los cuerpos. En el caso de haber sido enterrados, solo aparecerían 
las costras sedimentarias en la parte superior de cada unidad, en contacto entre las diferentes unidades estratigráficas y no de manera regular como es el caso. También son indicadoras de que no ha habido remoción para preparar las nuevas inhumaciones y, por lo tanto, refuerza la secuencia cronocultural obtenida durante la excavación.

Uno de los aspectos interesantes a considerar es la potencia de las costras sedimentarias. Su mayor potencia en la UE 1 podría deberse a diversos factores: a la mayor altura de esta unidad, lo que facilitaría la entrada de agua; a un deterioro del cierre de la entrada, actualmente perdida; y/o a mayores episodios de precipitaciones tormentosas.

Otra de las formaciones a destacar es la presencia de fosfatos autigénicos en las UUEe 2 y 12 que aparecen en los huesos formando hipo-revestimientos y revestimientos, así como, esencialmente nódulos distribuidos en la masa basal. Su origen estaría relacionado, principalmente con la propia disolución de los restos óseos debido a los ácidos orgánicos procedentes de la descomposición de los cuerpos que crearían un ambiente ácido y favorecerían la pérdida de la hidroxiapatita, fosfato cálcico, del hueso (Villagrán et al., 2017). Este entorno propiciaría la precipitación rápida del mismo en los restos óseos (Fig. 10).

La entrada de agua en el hipogeo sería uno de los agentes principales de los procesos postdeposicionales que han sufrido los restos óseos de los diferentes episodios de inhumación. Su diferente régimen hídrico habría provocado la distinta preservación de los restos del último episodio de inhumación -UE 1 - respecto los anteriores -UUEE 2 y 12-. Los fragmentos óseos afectados presentan una coloración amarilla/blanca muy pálida bajo LPP como resultado de la pérdida, en mayor o menor grado, de hidroxiapatita. Al mismo tiempo, este proceso favorece los aumentos de tamaño de los poros, lo que conduce a una intensificación progresiva de la dinámica de disolución, con contornos subredondeados (Hedges y Millard, 1995). El impacto que el agua tiene en los huesos depende del régimen hídrico -constante o intermitente-, de la porosidad del hueso y de los diferentes procesos químicos a los que están sometidos. Por lo tanto, el aumento de la disolución de los huesos de la ue 1 estaría relacionado con un incremento de las circulaciones de agua, tal como se ha contrastado en otros contextos arqueológicos (Bergadà et al., 2018; Polo y Fernández Eraso, 2010).

Finalmente, se aprecia una mayor estabilidad en el relleno de las UUEE 1 y 2 por la formación in situ de nódulos y colgantes de $\mathrm{CaCO}_{3}$ en el material detrítico y una mayor actividad de las raíces y fauna del suelo ocasionando la formación de un suelo, datos que nos sugieren que entre estas unidades estratigráficas y la superficie no había mucha distancia.

\section{Conclusiones}

El análisis micromorfológico ha demostrado que el enfoque geoarqueológico es esencial en este tipo de contextos. A partir de los datos obtenidos se ha podido caracterizar el proceso de construcción, el relleno arqueosedimentario, así como los diversos aspectos antrópicos que en él se realizaron. En el caso del hipogeo del Carrer París -Neolítico Final-Calcolítico Campaniforme-, se han podido establecer los diferentes periodos de construcción del mismo, el tipo de relleno de cada unidad estratigráfica, las actividades que se realizaron, los procesos postdeposicionales y sus efectos en el registro arqueológico.

Dos momentos de formación del hipogeo han sido documentados. El primero corresponde a la construcción y adecuación para su uso. Nos planteamos que esta fase se produjo con una clara antelación a las primeras inhumaciones. Por tanto, implica que sus constructores planearon y programaron su construcción sin vinculación a un uso inmediato. El segundo momento de formación del registro corresponde a la deposición de las diferentes inhumaciones. Parece que fueron depositadas en el suelo y posteriormente cubiertas por la disgregación del propio techo y paredes del hipogeo, sin observarse procesos de remoción posteriores. Esta disposición valida la secuencia cronocultural en base al material encontrado, hecho excepcional por la falta de registros estratigráficos fiables en estos periodos. 
Por otra parte, se han localizado componentes y áreas de combustión que sugieren que se realizaron en el interior del hipogeo, justo antes de depositar los primeros inhumados. De esta manera, se plantea que se produjo probablemente un ritual funerario, como ya se ha documentado en otros yacimientos de similar cronología en el NE peninsular.

Finalmente, también se ha determinado la complejidad de los procesos postdeposicionales. Algunos vinculados al aspecto tafonómico de los cuerpos enterrados con la aparición de la precipitación de fosfato autigénico generalmente en los propios huesos, así como la entrada de arroyadas difusas procedentes de la lluvia creando costras sedimentarias y afectando a los restos óseos de los distintos episodios de inhumación. Se han localizado, también, fases de estabilidad en el medio a través de la actividad biológica.

En resumen, esta contribución pone de manifiesto que los estudios microestratigráficos pueden ofrecer una lectura minuciosa y de alta resolución para plantear hipótesis sobre las manifestaciones funerarias de las comunidades en el pasado.

\section{Bibliografía}

Angelucci, D. E.; Boschian, G.; Fontanals, M.; Pedrotti, A. y Vergès, J. M. (2009): "Shepherds and karst: The use of caves and rock-shelters in the Mediterranean region during the Neolithic", World Archaeology, 41 (2), pp. 191-214.

Banerjea, R. Y.; Bell, M.; Matthews, W. y Brown, A. (2015): "Applications of micromorphology to understanding activity areas and site formation processes in experimental hut floors", Archaeological and Anthropological Sciences, 7, pp. 89-112.

Benyarku, C. A. y Stoops, G. (2005): Guidelines for preparation of rock soil thin sections and polished sections. Lleida: Univ. de Lleida.

Bergadì, M. M. (1993): “Aproximación experimental a la actividad postdeposicional de los lumbrícidos sobre los niveles arqueológicos”. En Actas $4 .^{\circ}$ Coloquio Internacional de Arqueología Espacial. Procesos Postdeposicionales. Teruel, pp. 363-369.
Bergadì, M. M. (1998): Estudio geoarqueológico de los asentamientos prehistóricos del Pleistoceno Superior y el Holoceno en Catalunya. Oxford: BAR Intern. Ser., 742. Oxford: Archaeopress.

Bergadà, M. M.; Cervelló, J. M.; Edo, M.; Antolín, F. y Martínez, P. (2018): "Procesos deposicionales $\mathrm{y}$ antrópicos en el registro holoceno de la Cova de Can Sadurní (Begues, Barcelona, España): aportaciones microestratigráficas", Boletín Geológico y Minero, 129 (1/2), pp. 251-284.

Bergadì, M. M.; Poch, R. M. y Cervelló, J. M. (2015): "On the presence of gypsum in the archaeological burial site of Cova des Pas (Menorca, Western Mediterranean)", Journal of Archaeological Science, 53, pp. 472-481.

Bertrán, P. y Texier, J. (1999): "Facies and microfacies of slope depòsits", Catena, 35, pp. 99-121.

Bronk Ramsey, C. (2009): "Bayesian analysis of radiocarbon dates Radiocarbon”. Radiocarbon, 51 (1), pp. 337-360.

Brönnimann, D.; Portmann, C.; Pichler, S. L.; Booth, T. J.; Röderd, B.; Vach, W.; Schibler, J. y Rentzel, P. (2018): "Contextualising the dead - Combining geoarchaeology and osteoanthropology in a new multi-focus approach in bone histotaphonomy", Journal of Archaeological Science, 98, pp. 45-58.

Bullock, P.; Fedoroff, N.; Jongerius, A.; Stoops, G. y BABEL, U. (1985): Handbook for soil thin section description. Albrighton: Wain Resarch Publication.

Canti, M. G. (2003): "Aspects of the chemical and microscopic characteristics of plant ashes found in archaeological soils", Catena, 54 (3), pp. 339-361.

Canti, M. G. (2007): "Deposition and taphonomy of earthworm granules in relation to their interpretative potential in Quaternary stratigraphy", Journal of Quaternary Science, 22 (2), pp. 111-118.

Canti, M. G. (2017): “Charred plant remains". En Stoops, G. y Nicosia, C. (eds.): Archaeological Soil and Sediment Micromorphology. Chichester: Blackwell Science Ltd., pp. 141-142.

Canti, M. G. y Piearce, T. G. (2003): "Morphology and dynamics of calcium carbonate granules produced by different earthworm species", Pedobiologia, 47, pp. 511-521.

Cardoso, J. L. (2019): "Los vasos campaniformes marítimos y su difusión desde el estuario del Tajo (Portugal)". En Delibes, G. y Guerra, E. (eds.): ¿Un brindis por el principe! El vaso Campaniforme en el interior de la Península Ibérica (2500-2000 a. C.). Madrid: MAR. pp. 109-134. 
Carlús, X. y De Castro, O. (2017): "L'establiment calcolític de Bosc del Quer (Sant Julià de Vilatorta, Osona). Estudi de les principals estructures i de les ceràmiques d'estil campaniforme", Cypsela, 20, pp. 63-84.

Clop, X. (2005): "La 'cuestión campaniforme' en el Noreste de la Península Ibérica”. En García, A. I.; GARRIDO, R. y Rojo, M. A. (eds.): El Campaniforme en la peninsula ibérica y su contexto europeo. Valladolid: Univ. de Valladolid, pp. 7-27.

Courty, M. A.; Goldberg, P. y Macphail, R. I. (1989): Soils and micromorphology in archeology. Cambridge: cup.

De Mas, D. (1989): El Relleu del Vallès Occidental: l'evolució geomorfològica quaternària del Vallès Occidental. Barcelona: Institut d'Estudis Catalans.

Dorronsoro, F.; Stoops, G.; Agullar, J.; Dorronsoro-Diaz, C.; Fernández, J.; Diez, M. y Dorronsoro, B. (2020): "Carbonatos en suelos. Programa sobre el proceso de acumulación y lavado de los carbonatos y de los rasgos resultantes de su actuación en los suelos". En Dorronsoro, F. (ed.): Libros web, monografias, trabajos de investigación, conferencias, atlas sobre la Edafología y los suelos. https://www.edafologia.net/

Ducloux, J. y Laouina, A. (1989): “The pendent calcretes in semi-arid climates: An example located near Taforalt, Nw Morocco", Catena, 16 (3), pp. 237-249.

Durand, N.; Monger, C. H. y Canti, M. G. (2010): "Calcium Carbonate Features". En Stoops, G. Marcelino, V. y Mees, F. (Eds.): Interpretation of Micromorphological Features of Soils and Regoliths. Amsterdam: Elsevier, pp. 149-194.

Fitzpatrick, E. A. (1990): Micromorfología de suelos. México: Compañía Editorial Continental.

FranCÈs, J.; GuÀrdia, M.; Majó, T. y Sala, Ò. (2006): "L'hipogeu calcolític del carrer de París de Cerdanyola del Vallès", Tribuna d'Arqueologia 2006-2007, 19 , pp. 315-333.

Ge, T.; Courty, M. A.; Matthews, W. y Wattez, J. (1993): "Sedimentary formation processes of occupation surfaces". En Goldberg, P.; Nash, M. D. y Petraglia, M. T. (eds.): Formation Processes in Archaeological Context. Monographs in World Archaeology, 17. Madison: Prehistory Press, pp. 149-163.

Gibaja, J. F.; Palomo, A. y Majó, T. (2006): "Les puntes de sageta de l'Hipogeu calcolític del carrer París (Cerdanyola): caracterizació tecnomorfològica i funcionial", Cypsela, 16, pp. 127-133.
Goldberg, P. y Macphail, R. I. (2006): Practical and theorical geoarcheology. Padstow: Blackwell.

Guilaine, J. (1958): "Où en est la question des vases campaniformes en France?", Bulletin de la Société Préhistorique Française, Lv, pp. 462-466.

Guilaine, J. (1967): La civilisation des vases campaniformes dans les Pyrénées françaises. Gabelle.

Guilaine, J. (1984): "La civilisation des vases campaniformes dans la France méridionale". En Guilaine, J. (ed.): L'Age du cuivre européen. Civilisations à vases campaniformes. París: CNRS, pp. 175-186.

Guilaine, J. (2019): "La question Campaniforme: sur quelques débats d'hier et d'aujourd'hui”, Estudos $\mathrm{Ar}$ queológicos de Oeiras, 25, pp. 9-46.

Guilaine, J.; Claustre, F.; Lemercier, O. y Philippe, S. (2001): "Campaniformes et environment culturel en France méditerranéenne". En Nicolis, F. (ed.): International Colloquium Riva del Grada (Trento, Italia) Bell Beakers today. Trento, pp. 229-275.

Hedges, R. E. y Millard, A. R. (1995): "Bones and Groundwater: Towards the Modelling of Diagenetic Processes", Journal of Archaeological Science, 22 (2), pp. 155-164.

Herrero, J. y Porta, J. (1987): "Gypsiferous soils in the North-East of Spain". En Fedoroff, N.; Bresson, L. M. y CourTy, M. A. (eds.): Micromorphologie des Sols, Soil Micromorphology. Plaisir: AFES, pp. 186-192.

Lomba, J.; López, M.; Ramos, F. y Avilés, A. (2009): "El enterramiento múltiple, calcolítico, de Camino del Molino (Caravaca, Murcia). Metodología y primeros resultados de un yacimiento excepcional", Trabajos de Prehistoria, 66 (2), pp. 143-159.

López, J. B.; Moya, A. y Martínez, P. (2015): "Els Reguers de Seró (Artesa de Segre, Catalogne): Un nouveau mégalithe avec des statues-menhirs anthropomorphes sculptées en réemploi". En La Mediterranée, Pierres levées et statues-menhirs au Néolithique (Saint-Pons-de-Thomières, 2012). Saint-Pons-deThomières, pp. 381-396.

Macphail, R. I. y Goldberg, P. (2010): "Archaeological materials". En Stoops, G.; Marcelino, V. y MeEs, F. (eds.): Interpretation of Micromorphological Features of Soils and Regoliths. Amsterdam: Elsevier, pp. 589-622.

Macphail, R. I. y Goldberg, P. (2018): Applied soils and micromorphology in Archaeology. Cambridge: cup.

Mallol, C.; Mentzer, S. M. y Miller, C. E. (2017): "Combustion Features". En Stoops, G. y NIcosia, C. (eds.): Archaeological Soil and Sediment 
Micromorphology. Chichester: Blackwell Science Ltd., pp. 299-330.

Martín, A. (2001): "État de la question du Campaniforme dans le contexte culturel chalcolithique du Nord-Est de la Péninsule Ibérique". En Nicolis, F. (ed.): International Colloquium Riva del Grada (Trento, 1998). Bell Beakers today. Trento, pp. 155-171.

Mateu, M.; Bergadè, M. M.; Armada, X. y Rafel, N. (2019): "Micromorphology of the Early Iron Age semi-cemented floors : El Calvari del Molar (Tarragona, NE Spain) as case study", Journal of Archaeological Science: Reports, 23, pp. 746-762.

Mentzer, S. M. (2014): "Microarchaeological Approaches to the Identification and Interpretation of Combustion Features in Prehistoric Archaeological Sites", Journal of Archaeological Method and Theory, 21 (3), pp. 616-668.

Miller, C. E.; Conard, N. J.; Goldberg, P. y BerNA, F. (2009): "Dumping, sweeping and trampling: Experimental micromorphological analysis of anthropogenically modified combustion features", P@ lethnologie, 2, pp. 25-37.

Morrás, H. (2015): "Porosidad y microestructuras de suelos”. En Loaiza, J. C.; Stoops, G.; Росн, R. M. y Casamitjana, M. (eds.): Manual de micromorfología de suelos y técnicas complementarias. Medellín: Pasqual Bravo, pp. 205-249.

Mücher, H.; Van Steijn, H. y Kwaad, F. (2010): “Colluvial and Mass Wasting Deposits". En Stoops, G.; Marcelino, V. y Mees, F. (eds.): Interpretation of Micromorphological Features of Soils and Regoliths. Amsterdam: Elsevier, pp. 37-48.

Olalde, I.; Brace, S.; Allentoft, M. y Reich, D. (2018): "The beaker phenomenon and the genomic transformation of Northwest Europe", Nature, 555, pp. 190-196.

Oms, F. X.; Mestres, J.; Cebrià, A.; Morales, J. I.; Mendiela, S. y Pedro, M. (2018): "Primers resultats sobre la seqüència del neolític final al bronze final c. 3350-900 cal. a. C. a la Cova de la Guineu (Font-rubí, Alt Penedès, Barcelona)", Tribuna d'Arqueologia 2014-2015, pp. 254- 266.

Pagliai, M. y Stoops, G. (2010): "Physical and Biological Surface Crusts and Seals. En Stoops, G.; Marcelino, F. y Mees, F. (eds.): Interpretation of Micromorphological Features of Soils and Regoliths. Amsterdam: Elsevier, pp. 419-440.

Polo Díaz, A. y Fernández Eraso, J. (2010): “Same anthropogenic activity, different taphonomic processes: A comparison of deposits from Los Husos I \& II (Upper Ebro Basin, Spain)", Quaternary International, 214 (1-2), pp. 82-97.

Reimer, P. J.; Bard, E.; Bayliss, A.; Beck, J. W.; Blackwell, P. G.; Bronk Ramsey, C.; Buck, C. E.; Cheng, H.; Edwards, R. L.; Friedrich, M.; Grootes, P. M.; Guilderson, T. P.; Haflidason, H.; Haidas, I.; Hatté, C.; Heaton, T. J.; Hoffmann, D. L.; Hogg, A. G.; Hughen, K. A.; Kaiser, K. F.; ... y Van Der Plicht, J. (2013): "IntCal13 and Marine13 radiocarbon age calibration curves $0-50,000$ years cal вР", Radiocarbon, 55 (4), pp. 1869-1887.

Roig, J.; Molina, D.; Coll, J. M. y Molina, J. A. (2008): "El jaciment calcolític del Vapor Gorina (Sabadell, Vallès Occidental)", Tribuna d'Arqueologia 2007, pp. 93-122.

Salanova, L. (1998): "A long way to go... The Bell Beaker chronology in France”. En Benz, M. y Van Willigen, S. (eds.): Some New Approaches to The Bell Beaker "Phenomenon"- Lost Paradise...? Proceedings of the 2nd Meeting of the Association Archéologie et Gob. Feldberg (Germany), 1997. Oxford: Hadrian Books.

Soriano, I. (2013): Metalurgia y Sociedad en el Nordeste de la Peninsula Ibérica (finales del IV-II milenio cal. a.n.e.). BAR Intern. Ser., 2502. Oxford: Archaeopress.

Soriano, I. (2017): "Les pràctiques funeràries durant el calcolític i el bronze antic i mitjà". En Bosch, J.; BoRRELl, M. y Garrido, A. M. (eds.): La fi és el principi. Barcelona: MARC, pp. 79-101.

Stoops, G. (2003): Guidelines for Analysis and Description of Soil and Regolith Thin Sections. Madison: Soil Science Society of America.

Stoops, G.; Marcelino, V. y Mees, F. (2010): Interpretation of Micromorphological Features of Soils and Regoliths. Amsterdam: Elsevier.

TARrús, J. (2002): Poblats, dòlmens i menhirs. Els grups megalitics de l'Albera, serra de Rodes i cap de Creus. Girona: Diput. de Girona.

Vilaseca, S. (1973): Reus y su entorno en la Prehistoria. Vol. I. Reus: Asociación de Estudios Reusenses.

Villagrán, X. S.; Huisman, D. J.; Mentzer, S. M.; MiLLER, C. E. y Jans, M. M. (2017): "Bone and Other Skeletal Tissues”. En Stoops, G. y Nicosia, C. (eds.): Archaeological Soil and Sediment Micromorphology. Chichester: Blackwell Science Ltd., pp. 11-38.

Wieder, M. y YaAlon, D. H. (1974): "Effects of matrix composition on carbonate nodule crystallization", Geoderma, 11, pp. 95-121. 